Review

\title{
Recent Progress in N-Heterocyclic Carbene Gold-Catalyzed Reactions of Alkynes Involving Oxidation/Amination/Cycloaddition
}

\author{
Xiang-Ting Tang, Fan Yang, Ting-Ting Zhang, Yi-Fan Liu, Si-Yu Liu, Tong-Fu Su, Dong-Can Lv \\ and Wen-Bo Shen * \\ College of Sciences, Henan Agricultural University, Zhengzhou 450001, Henan, China; \\ xiangting7544@gmail.com (X.-T.T.); yangfan052407@gmail.com (F.Y.); zhangtingting0809@gmail.com (T.-T.Z.); \\ 13461008603lyf@gmail.com (Y.-F.L.); s579797888@163.com (S.-Y.L.); sutongfusua@126.com (T.-F.S.); \\ lvdongcan0118@163.com (D.-C.L.) \\ * Correspondence: wenboshen@henau.edu.cn
}

Received: 25 February 2020; Accepted: 12 March 2020; Published: 20 March 2020

\begin{abstract}
Recent rapid development in homogeneous gold catalysis affords an alternative and particularly thriving strategy for the generation of gold carbenes through gold-catalyzed oxidation/amination/cycloaddition of alkynes, while it avoids the employment of hazardous and potentially explosive diazo compounds as starting materials for carbene generation. In addition to facile and secure operation, gold carbenes generated in this strategy display good chemoselectivity distinct from other metal carbenes produced from the related diazo approach. $\mathrm{N}$-heterocyclic carbene (NHC) gold is a special metal complex that can be used as ancillary ligands, which provides enhanced stability and can also act as an efficient chiral directing group. In this review, we will present an overview of these recent advances in alkyne oxidation/amination/cycloaddition by highlighting their specificity and applicability, aiming to facilitate progress in this very exciting area of research.
\end{abstract}

Keywords: $N$-heterocyclic carbene; gold complexes; oxidation; amination; cycloaddition

\section{Introduction}

$\mathrm{N}$-heterocyclic carbenes (NHC), since the first isolation of a metal-free imidazol-2-ylidene by Arduengo and coworkers in 1991 [1], have become one of the most extensively investigated ligands for transition metal complexes [2-12]. Far from being just a curiosity, NHC have also played ubiquitous and indispensable roles in a wider range of fields such as homogeneous catalysis [13-17], materials science [18-22], organocatalysis [23,24], and even medicinal chemistry [25-28]. NHC as ancillary ligands can been widely applied in transition metal chemistry, and homogeneous catalysis, presumably due to forming the highly robust bonds between the soft carbon donors of NHC with soft metals [3,13-16,29,30]. Compared to the corresponding phosphine ligands, NHC-complexes have stronger metal-carbon $\sigma$-bonds and exhibit higher activities [2,17,31-39]. In addition, a diverse array of NHC with various ring sizes, ring backbones, heteroatoms and $N$-substituents have been readily prepared [40]. Among those, the most versatile representative of exceedingly steady NHC is the five-membered NHC [29], owing to proximal $\sigma$-electron-withdrawing and $\pi$-electron-donating nitrogen atoms next to the carbene carbon atom (Figure 1). 


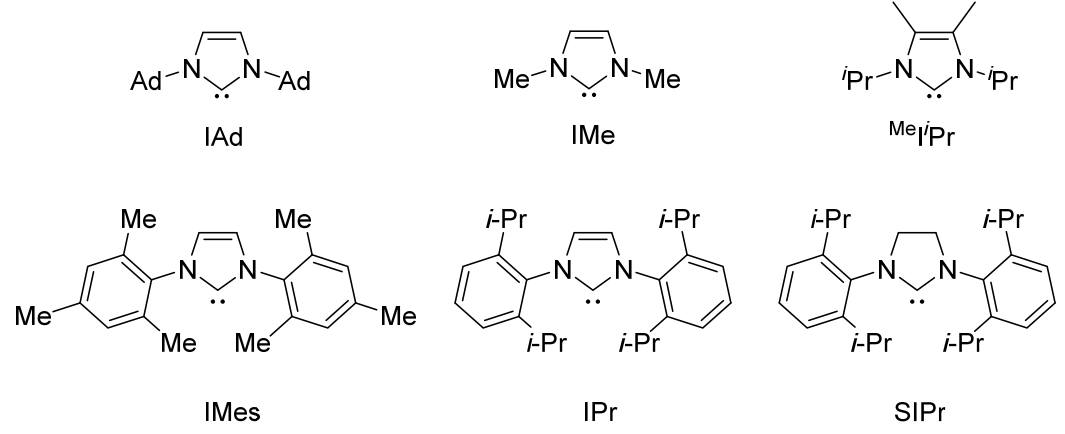

Figure 1. Frequently utilized $N$-heterocyclic carbenes and their acronyms. Ad = adamantanyl.

In past decades, homogeneous gold catalysis has been proved to be an extremely powerful approach in organic synthesis, owing to its high catalytic activities, benign reaction conditions and good tolerance of various functional groups, for the facile and practical construction of cyclic compounds, especially the heterocycles [41-66]. This strategy avoids the employment of hazardous and potentially explosive diazo compounds as starting materials for carbene generation. The generation of gold carbene, which is highly reactive and highly electrophilic, from readily available alkynes represents a significant advance in metal carbene chemistry. Substantial progress has been achieved in the synthesis and organometallic chemistry of Au-NHC complexes. The breadth of important structural skeletons, which can be constantly observed in bioactive molecules as well as in natural products, have been efficiently constructed through NHC gold-catalyzed oxidation/amination/cycloaddition of alkynes (Figure 2). It is surprising, however, that the review of catalytic oxidation/amination/cycloaddition of alkynes by the NHC gold complexes have seldom been reported, although significant advances have been achieved during recent years.

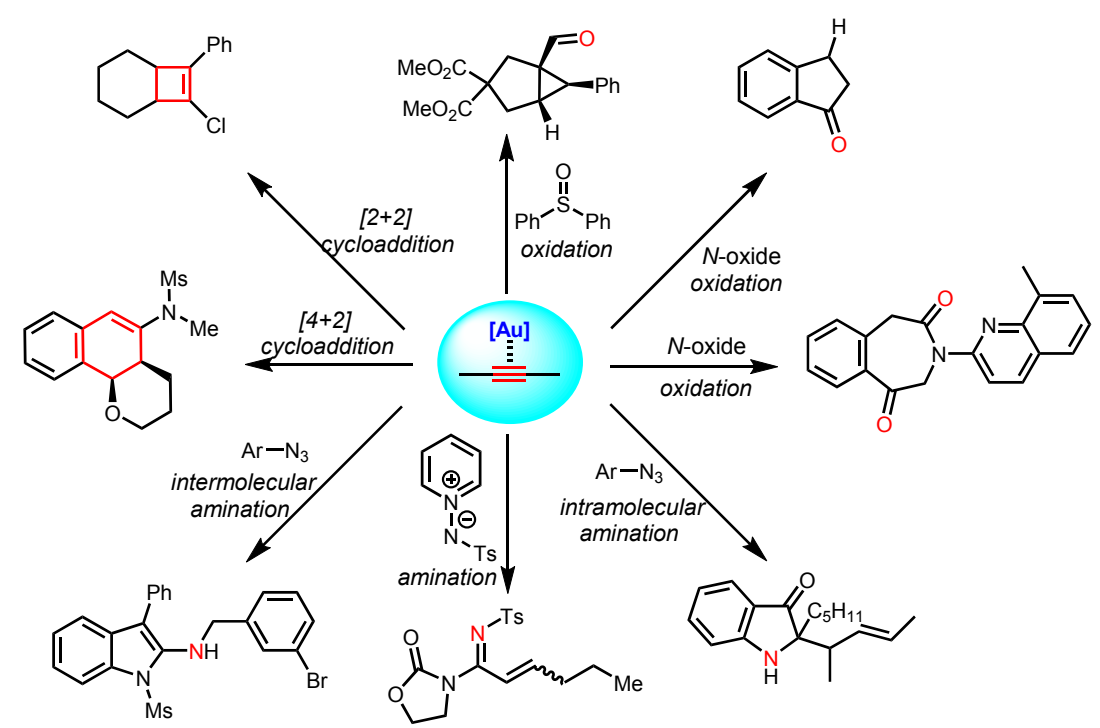

Figure 2. $N$-heterocyclic carbene gold-catalyzed tandem reactions of alkynes.

This review introduces an overview of NHC gold-catalyzed reactions of alkynes involving oxidation/amination/cycloaddition in the past thirteen years. In order to fully profile relevant reactions, a brief description of a reported previous study will also be presented. Although gold complexes featuring phosphine analogues as ligands have been synthesized and applied in catalysis $[67,68]$, this review article summarizes the results obtained with the NHC used as ligands. Herein, we wish to focus the current review article on the catalytic aspect of $\mathrm{Au}-\mathrm{NHC}$ chemistry, in particular, the recent progress of reactions of alkynes involving oxidation/amination/cycloaddition enabled by $\mathrm{Au}-\mathrm{NHC}$ complexes. 


\section{NHC Gold-Catalyzed Alkyne Oxidation}

\subsection{Synthesis of Cyclopropyl Aldehydes Involving Oxygen Atom Transfer to Gold Carbene}

In 2007, Toste and coworkers reported an elegant protocol for the NHC gold-catalyzed oxidative transformations of alkynes by employing sulfoxides as oxidants to afford a variety of cyclopropyl aldehydes in excellent yields [69]. It is worth noting that the carbene nature of the intermediates was further confirmed though the oxygen atom transfers from a sulfoxide to a cationic gold (I) species. It was found that the reaction of 1,6-enynes 1 with 2 equivalent of diphenylsulfoxide $2 \mathrm{a}$ afforded successfully a series of cyclopropyl aldehydes 3 in $75 \%-94 \%$ isolated yields with broad substrate scope by using $\mathrm{IPrAuCl} / \mathrm{AgSbF}_{6}(2.5-5 \mathrm{~mol} \%)$ as the catalyst (Scheme 1). The aryl- and vinyl-substituted 1,6 -enynes were suitable substrates for this tandem reaction, providing the corresponding products in $75 \%-90 \%$ isolated yields. In addition, heteroatom-linked 1,6-enynes were also further screened and transformed smoothly into the desired heterocycles in $91 \%-94 \%$ isolated yields.

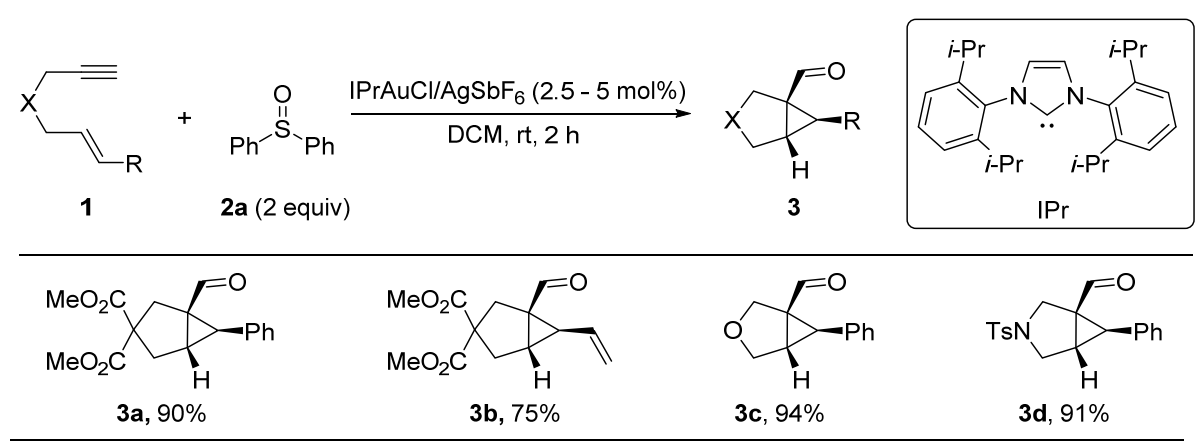

Scheme 1. Synthesis of cyclopropyl aldehydes 3.

Moreover, if the substrate with a methyl substituent at the $\beta$ position to the terminal double bond was examined, this transformation implemented smoothly, leading to the cyclopentenyl aldehyde 5a rather than the expected cyclopropanation product via skeletal rearrangement (Scheme 2). Skeletal rearrangement of 1, 6-enyne 4a presumably proceeded via gold carbene intermediate.

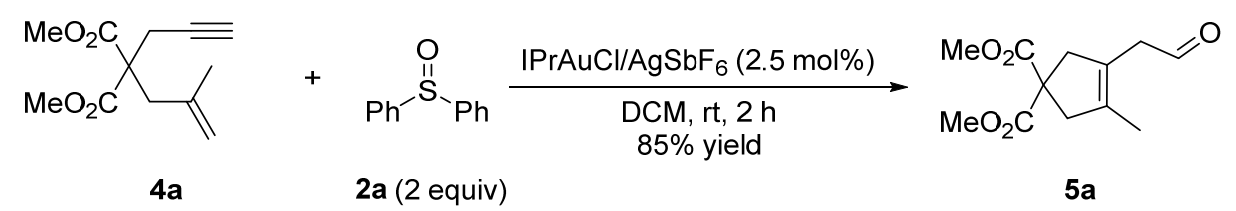

Scheme 2. Synthesis of cyclopentenyl aldehyde 5a through skeletal rearrangement.

Toste et al. gave a plausible mechanism for the formation of cyclopropyl aldehydes 3 based on a series of control experiments (Scheme 3). Initially, coordination of the alkyne to the catalytic $\left[\mathrm{Au}^{\mathrm{I}}\right]$-species facilely formed precursors 1-A, which then evolved to afford the gold cyclopropyl carbene complexes 1-B via a presumable 5-exo-dig cyclization. Subsequently, dimethylsulfoxide 2a nucleophilically attacked the gold carbenes 1-B to yield the cyclopropyl aldehydes 3 through intermediates 1-C concomitant with a $\mathrm{S}-\mathrm{O}$ bond cleavage. 


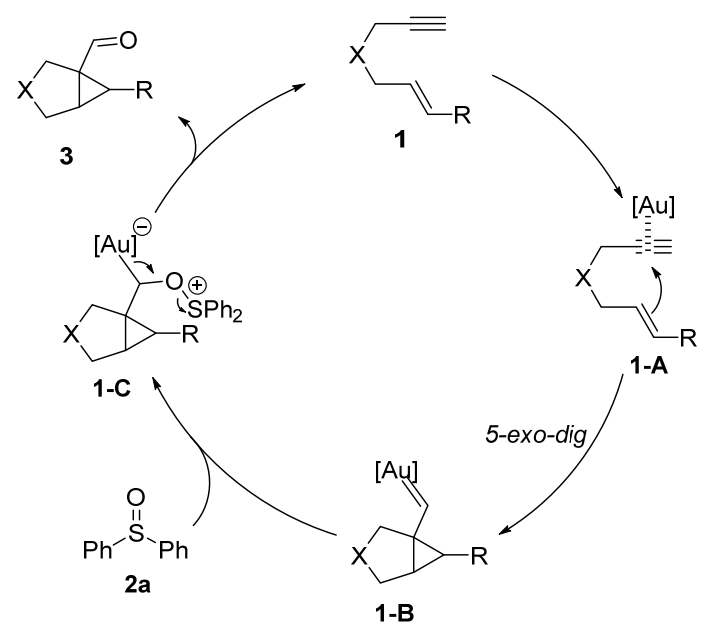

Scheme 3. Mechanistic proposal for N-heterocyclic carbenes (NHC) gold-catalyzed synthesis of cyclopropyl aldehydes 3 .

\subsection{Synthesis of $\beta$-Hydroxyenones through Pinacol Rearrangement}

In 2007, Zhang and coworkers discovered a novel procedure for the NHC gold-catalyzed Intramolecular redox reaction of sulfinyl alkynes, leading to a series of $\beta$-hydroxyenones in $58 \%-75 \%$ isolated yields [70]. Notably, this protocol provided a two-step insertion of a latent vinylcarbonylmethylene group into carbonyl group and avoided using potentially explosive diazo compounds [71-76]. In the presence of $5 \mathrm{~mol} \%$ of $\mathrm{IPrAuNTf}_{2}$, phenyl sulfoxides 6 could be facilely converted into a variety of $\beta$-hydroxyenones 7 (Scheme 4). Of particular note is that substituents with a different electronic nature on the aromatic rings were readily tolerated. This tandem reaction took place smoothly and the desired dicarbonyl products were exclusively obtained with selective phenyl migration.
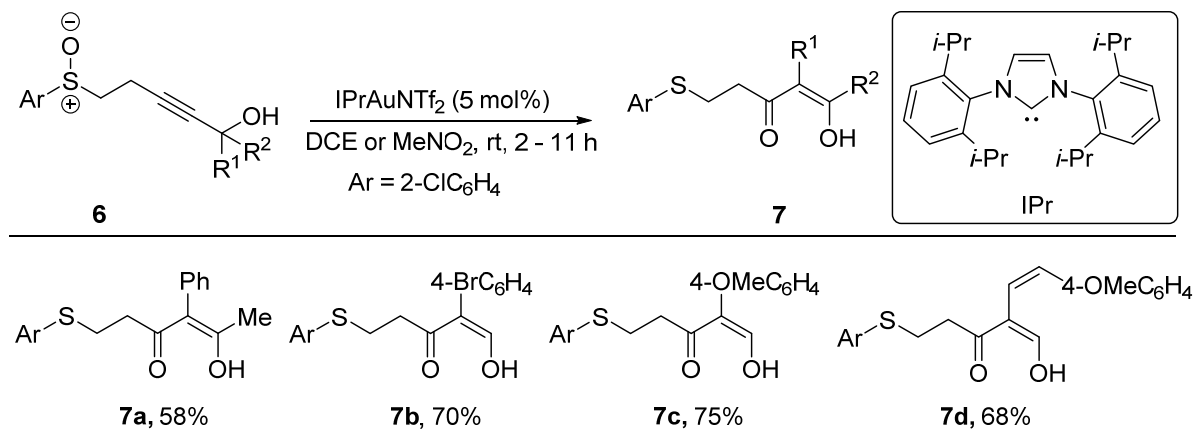

Scheme 4. Synthesis of $\beta$-hydroxyenones 7 via pinacol rearrangement.

On the basis of the experimental observations, a plausible mechanism for this transformation was illustrated (Scheme 5). Firstly, intramolecular nucleophilic addition of S-O to the Au(I)-ligated triple bond generated successfully the $\alpha$-oxo gold carbene intermediates 6-B through the vinyl gold intermediates 6-A. Subsequently, migration of $\mathrm{R}^{1}$ to the gold carbenes occurred smoothly to afford the final $\beta$-hydroxyenones 7 via the intermediate $6-\mathrm{C}$. 


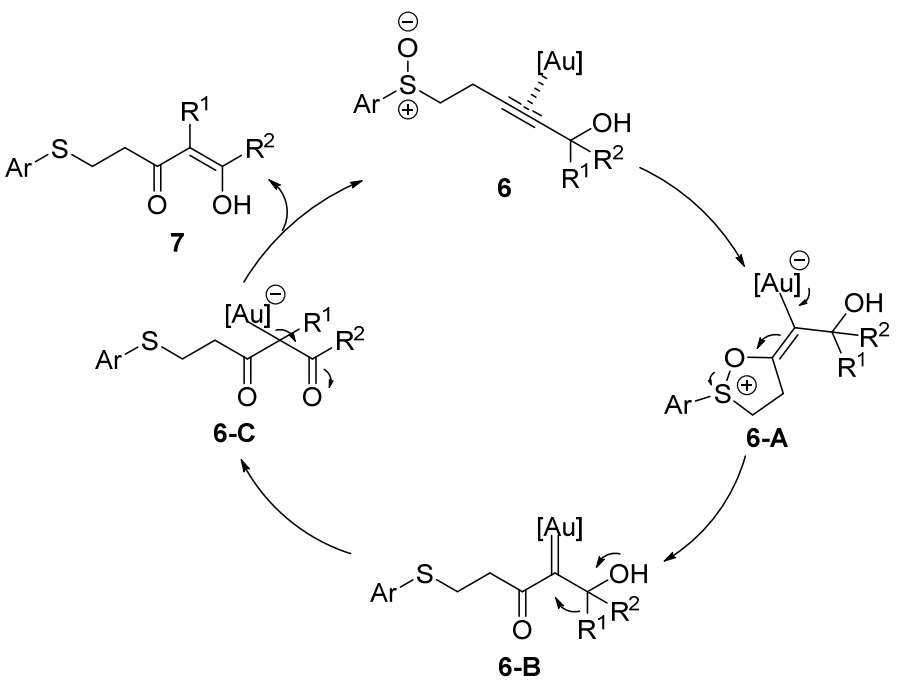

Scheme 5. Plausible mechanism for the formation of $\beta$-hydroxyenones 7.

\subsection{Synthesis of $\alpha, \beta$-Unsaturated Carbonyls without Acid Additives}

Later, the same group developed a successful case of NHC gold-catalyzed intermolecular oxidations of internal alkynes by employing 8-isopropylquinoline $N$-oxide as oxidants, leading to the breadth of $\alpha, \beta$-unsaturated carbonyls in good yields and with excellent $E$-selectivities [77]. This synthetic tool provided an efficient masking of $\alpha, \beta$-unsaturated carbonyls as propargyl moieties, yielding a flexible and general solution to compatibility issues including $\alpha, \beta$-unsaturated carbonyl compounds. In this study, $\alpha$-oxo gold carbene generated from the alkyne oxidation proceeded smoothly $1,2-\mathrm{C}-\mathrm{H}$ insertions instead of further oxidation. As depicted in Scheme 6, the reaction of aliphatic alkynes 8 with 1.2 equivalent of 8-isopropylquinoline $N$-oxide 9 a afforded smoothly the bulk of $\alpha, \beta$-unsaturated carbonyl compounds 10 by employing $\operatorname{IPrAuNTf}_{2}$ as the catalyst in the absence of acid additives. A variety of readily available substituted aliphatic alkynes was further examined and the corresponding products were merely obtained in 78\%-92\% isolated yields with high regioselectivity. This approach exhibited good functional group compatibility and the alkynes with sensitive functional groups, such as OMOM (methoxymethyl), $\mathrm{N}_{3}$ and OTHP (2-tetrahydropyranyl), were well tolerated in all these cases.

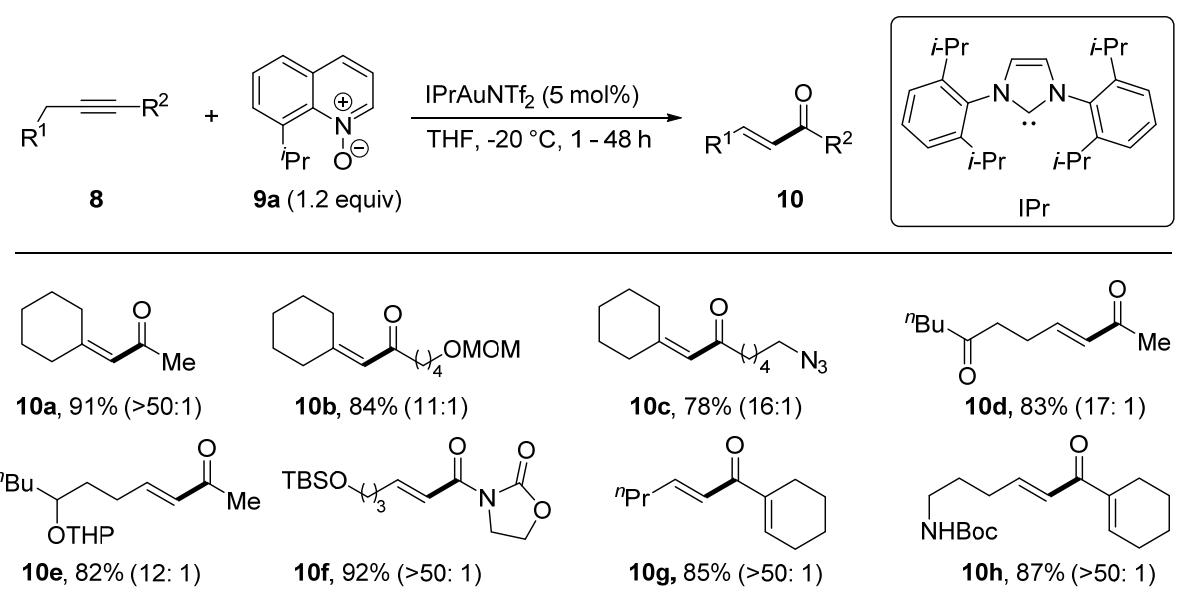

Scheme 6. Synthesis of $\alpha, \beta$-unsaturated carbonyls 10 .

\subsection{Synthesis of Cyclopentenone Derivatives via C-H Activation}

In 2012, Liu and coworkers reported a new synthetic approach for the construction of cyclopentenone derivatives involving a NHC gold-catalyzed intermolecular oxidation reaction of 
cis-substituted 3-en-1-ynes by employing quinoline $\mathrm{N}$-oxide as oxidant [78]. A 1,5-hydrogen shift of formed gold-containing enol ether, rather than a carbene route, was probably the key step for this tandem reaction. As outlined in Scheme 7, enynes 11 with 3 equivalent of 8-methylquinoline $N$-oxide $9 \mathbf{b}$ could be readily transformed into a plethora of cyclopentenone derivatives 12 in 63-90\% isolated yields with $\mathrm{IPrAuCl} / \mathrm{AgNTf}_{2}(5 \mathrm{~mol} \%$ ) as the catalyst. Alkyl-substituted enynes were suitable substrates for this transformation to produce the desired products. Aromatic substrates bearing electron-withdrawing or electron-donating substituents on the phenyl ring also reacted well to smoothly yield the corresponding products in $63 \%-85 \%$ isolated yields. Furthermore, the alkyl-substituted substrates could also efficiently proceed to generate the desired products in $67 \%-90 \%$ isolated yields.

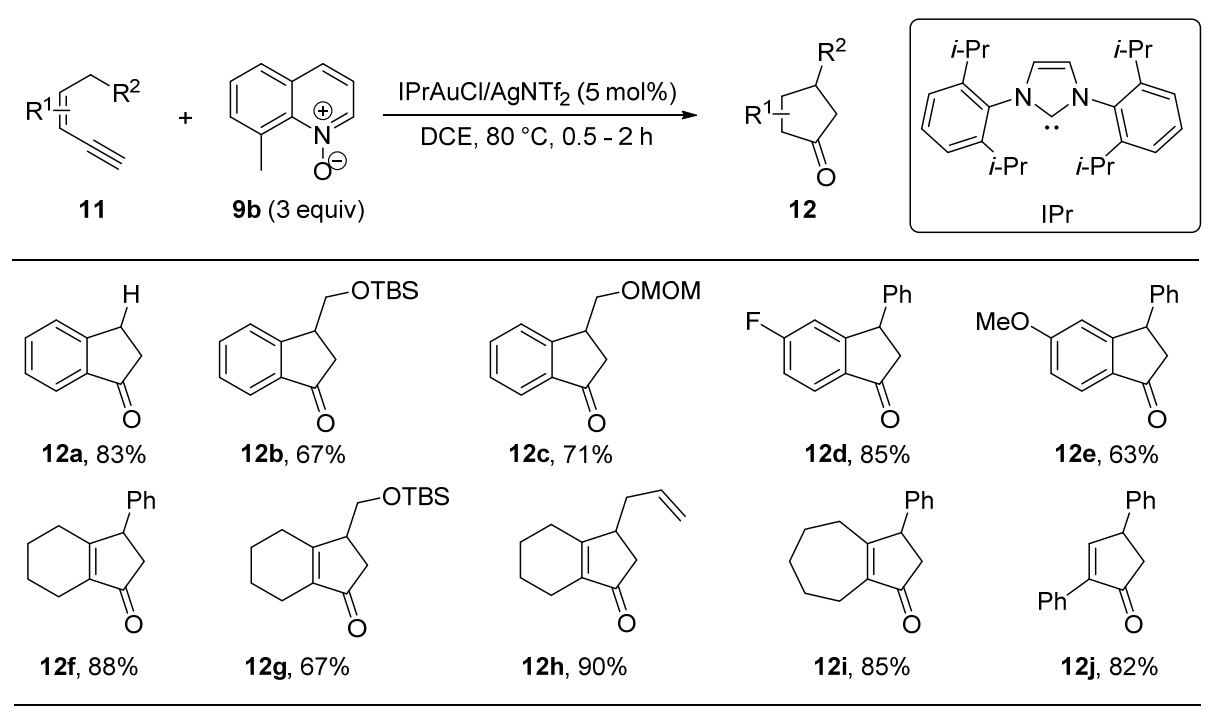

Scheme 7. Synthesis of cyclopentenone derivatives involving C-H activation 12.

A possible mechanism to rationalize the formation of $\mathbf{1 2}$ was presented in Scheme 8. Nucleophilic attack of 8-methylquinoline $\mathrm{N}$-oxide $\mathbf{9 b}$ on the $\left[\mathrm{Au}^{\mathrm{I}}\right]$-ligated terminal $\mathrm{C}-\mathrm{C}$ triple bond of enynes 11-A formed smoothly vinyl gold intermediates 11-B. Subsequently, a rapid 1,5-hydrogen shift [79-82] occurred uniquely to provide the species 11-C, which further underwent a intramolecular cyclization to form the expected products 12 .

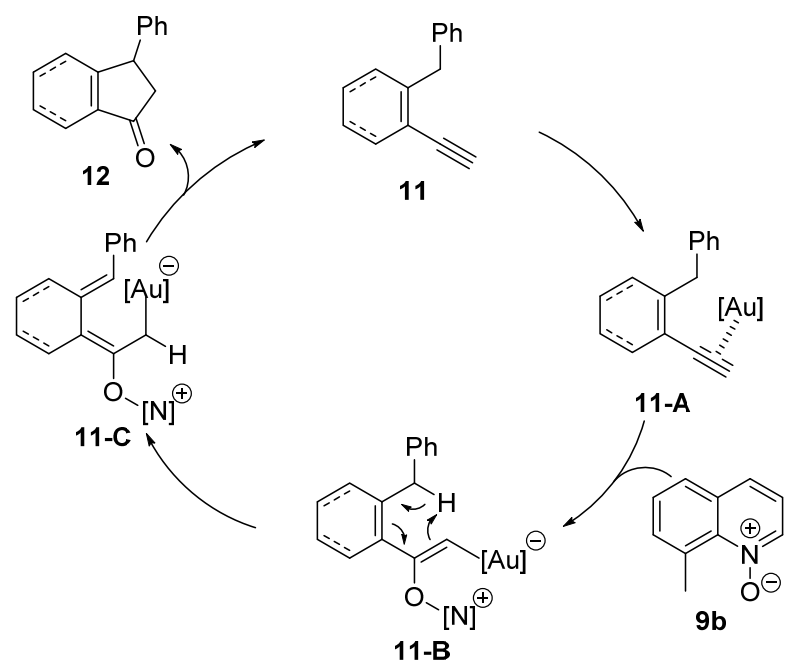

Scheme 8. Plausible mechanism for the formation of cyclopentenone derivatives $\mathbf{1 2 .}$ 


\subsection{Synthesis of Oxoarylated Compounds Involving Seven-Membered Cyclic Nitriliums}

Following this work, the same group described a procedure of NHC gold-catalyzed oxoarylations of nitriles with pyridine-derived $N$-oxides by utilizing gold carbenes as initiators [83]. More importantly, this protocol was the first examples of the oxidations of nitriles with organic $\mathrm{N}$-oxides to form oxoarylation products. In addition, it was found that a key intermediate seven-membered cyclic nitriliums could be involved. Nitriles 13 with 3 equivalent of pyridine-derived $N$-oxide 14 could be easily converted into the bulk of oxoarylation products in $31 \%-84 \%$ isolated yields by utilizing $\mathrm{IPrAuSbF}_{6}$ ( $5 \mathrm{~mol} \%$ ) as the catalyst (Scheme 9). The scope of the transformation was further explored with a series of substituted nitriles and the substrates bearing both electron-donation and electron-withdrawing on the aromatic were compatible with this relay transformation. The reaction proceeded smoothly with different 2-substituted pyridine $\mathrm{N}$-oxides, yielding the desired oxoarylation products.
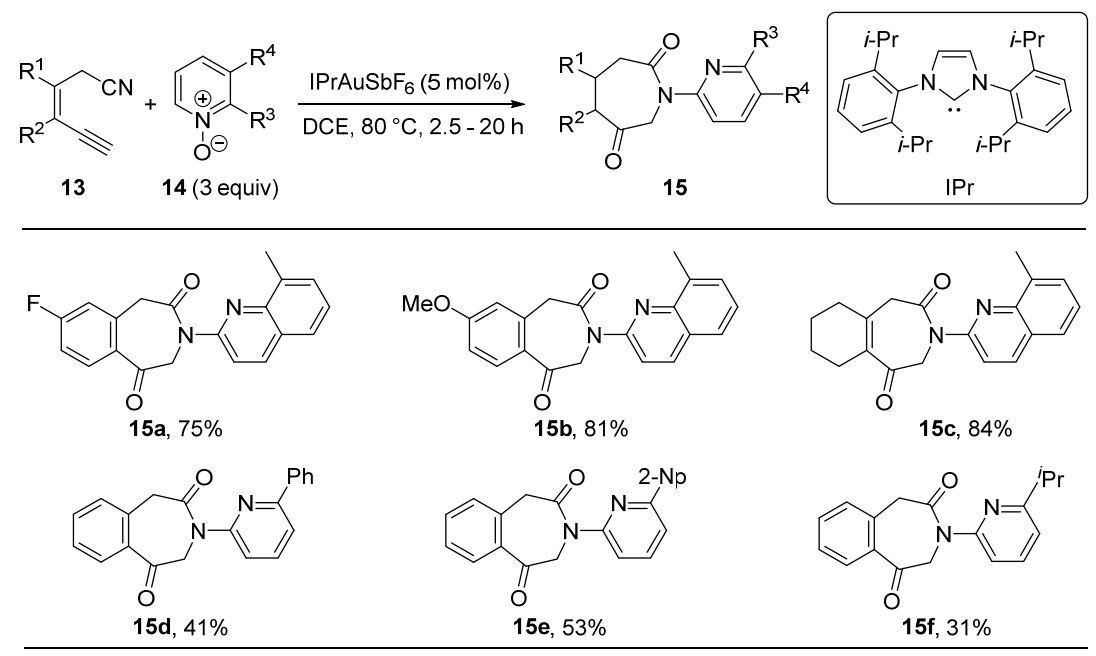

Scheme 9. Synthesis of oxoarylation compounds 15.

Liu et al. gave a plausible mechanism for the formation of oxoarylation compounds $\mathbf{1 5}$ based on a series of control experiments (Scheme 10). Firstly, nucleophilic attack of pyridine-derived $N$-oxides 14 on the $\left[\mathrm{Au}^{\mathrm{I}}\right]$-ligated terminal $\mathrm{C}-\mathrm{C}$ triple bond of nitriles 13 readily afforded terminal $\alpha$-oxo gold carbenes 13-A, concomitant with a $\mathrm{N}-\mathrm{O}$ bond cleavage, that induced an attack of the tethered nitrile to give the seven-membered nitrilium species 13-B. The species 13-B were further trapped by external $\mathrm{N}$-oxide to deliver the azacyclic species $13-\mathrm{C}$, followed by a ring cleavage yielding the oxoarylation compounds 15.

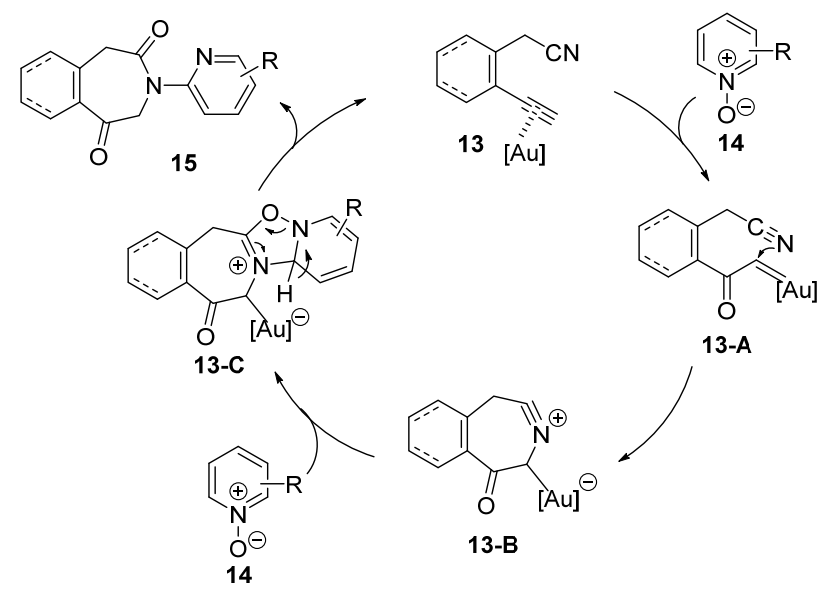

Scheme 10. Mechanistic proposal for the formation of oxoarylation compounds $\mathbf{1 5 .}$ 


\subsection{Synthesis of Silylketenes through Wolff Rearrangement}

Only very recently, Zhang and coworkers discovered an elegant protocol for the facile and straightforward synthesis of a wealth of valuable silylketenes through NHC gold-catalyzed oxidative rearrangement of TBS ( $t$-butyldimethylsilyl)-terminated alkynes with quinoline $\mathrm{N}$-oxide [84]. It should be noted that this was the first example of the Wolff rearrangement by oxidatively generated $\alpha$-oxo gold carbene species. Furthermore, the mechanism of this procedure which $\alpha$-oxo gold carbene was formed through the gold-catalyzed alkyne oxidation was distinctively different from the related rhodium/ruthenium-catalyzed reactions where $\mathrm{Rh} / \mathrm{Ru}$ vinylidene intermediates were involved. In addition, the silylketenes could be transformed readily into the corresponding thioesters in a one-pot process. In the presence of $10 \mathrm{~mol}^{\%}$ of $\mathrm{IPrAuSbF}_{6}$ and $10 \mathrm{~mol} \%$ of NaBARF, TBS-terminated alkynes 16 with 2 equivalent of 8-isopropylquinoline $N$-oxide 9 a could be transformed successfully into the silylketenes, which reacted with thiophenol 18a to offer the thioesters 19 in $63 \%-85 \%$ isolated yields (Scheme 11). Alkynes containing substituents with a different electronic nature on the aromatic rings were also suitable substrates, and were indeed converted into the expected products. In particular, this method was tolerant of various functional groups including the heteroaryls, a nonfunctionalized alkyl chain and sensitive THP-protected $\mathrm{OH}$ group.

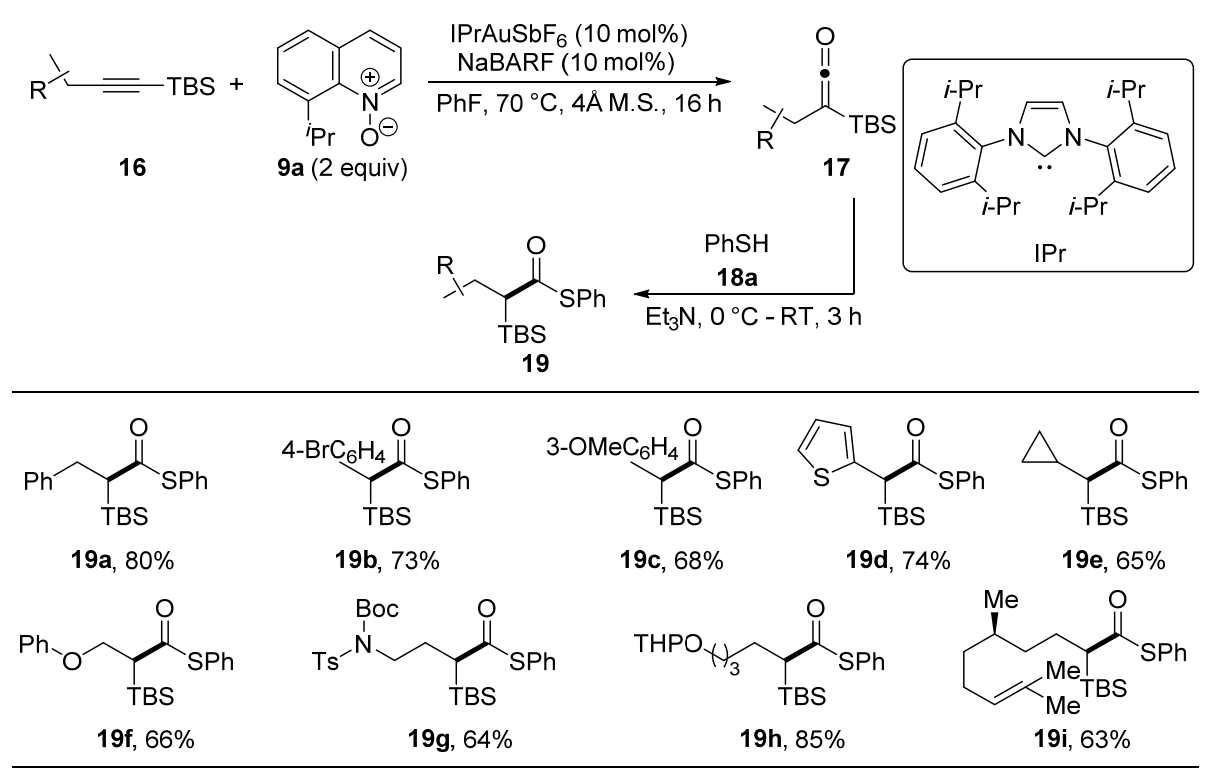

Scheme 11. Synthesis of silylketenes 19 in a one-pot process. NaBARF = sodium tetrakis [3,5-bis(trifluoromethyl) phenyl]borate. M.S. = molecular sieves.

\section{NHC Gold-Catalyzed Alkyne Amination}

\subsection{Synthesis of Pseudoindoxyl and Indolyl Frameworks Involving Markovnikov Addition}

In 2011, Gagosz and coworkers reported that NHC gold-catalyzed amination cyclization of 2-alkynyl arylazides with allyl alcohols enabled facile synthesis of a plethora of indolin-3-ones [85]. A series of allylic alcohols was first examined, and the corresponding products were efficiently obtained in 59\%-92\% isolated yields (Scheme 12). This catalytic reaction offered a broad substrate scope and excellent functional group tolerance, and the electronic property of aryl groups (electron-rich or electron-poor) on the aromatic ring did not have a significant impact. 

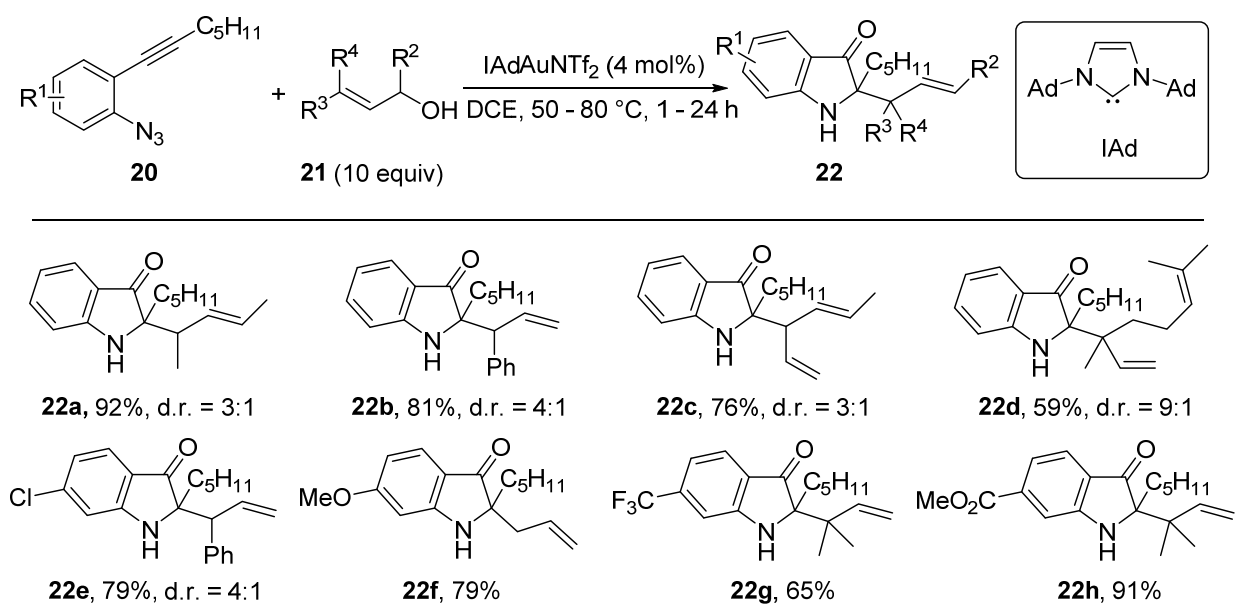

Scheme 12. Synthesis of indolin-3-ones 22 by way of Markovnikov addition. Ad = adamantanyl.

Moreover, this chemistry was also extended successfully to other nucleophiles and a wealth of 3-substituted indoles were exclusively formed rather than the corresponding indolin-3-ones, probably because these nucleophiles would not be suitable for the Claisen rearrangement (Scheme 13). Besides, water was also a suitable substrate for this tandem reaction to yield the expected product in $89 \%$ isolated yield.
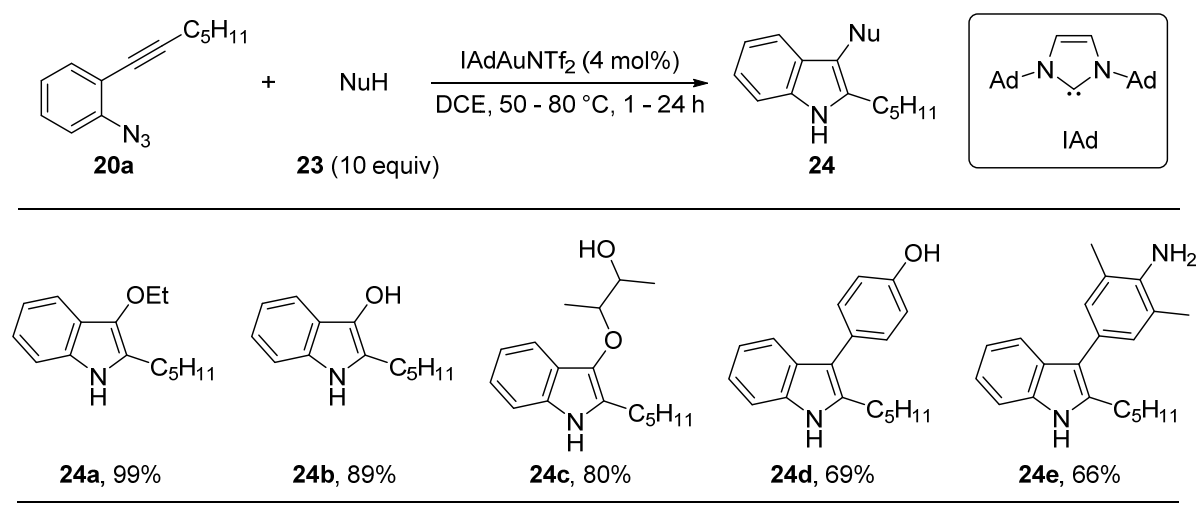

Scheme 13. Synthesis of 3-substituted indoles 24. Ad = adamantanyl. $\mathrm{NuH}=$ nucleophiles.

A possible mechanism to elucidate the formation of indolin-3-ones 22 was presented in Scheme 14. The activation of the triple bond by the NHC gold(I) complex was first attacked by the azide group, leading to the $\alpha$-imino gold carbenes 20-A. Gold carbenes were further trapped by the allyl alcohols 21f to generate the indolin species 20-C via the intermediates 20-B, which preferentially underwent a Claisen rearrangement to furnish the final indolin-3-ones 22.

\subsection{Synthesis of $\alpha, \beta$-Unsaturated Amidines through Nitrene-Transfer Reagents}

Later, Zhang and coworkers disclosed a novel route to the generation of $\alpha$-imino gold carbenes through NHC gold-catalyzed intermolecular nitrene transfer to alkynes, thus realizing a new nitrene transfer strategy [86]. A series of nitrene-transfer reagents were evaluated, and iminopyridium ylides especially those based on 3,5-dichloropyridine proven to be extremely effective. Moreover, the mechanism of this mode was different from previous nitrene transfer reactions as the nitrene moiety was generated from an outer sphere attack rather than gold nitrene complex. The reaction of activated alkynes 25 with 1.2 equivalent of iminopyridinium ylide 26a yielded smoothly the bulk of the $\alpha$, $\beta$-unsaturated amidines 27 by employing $\operatorname{IPrAuNTf}_{2}(5 \mathrm{~mol} \%)$ as the catalyst (Scheme 15). The alkynes substituted at the alkyne terminus by a primary alkyl group and several functionalized ones were also 
suitable substrates and were transferred facilely to the desired $\alpha, \beta$-unsaturated amidines. In addition to tosylnitrene, other arenesulfonylnitrenes were then screened and the expected $\alpha, \beta$-unsaturated amidines were efficiently obtained in $79 \%-88 \%$ isolated yields.

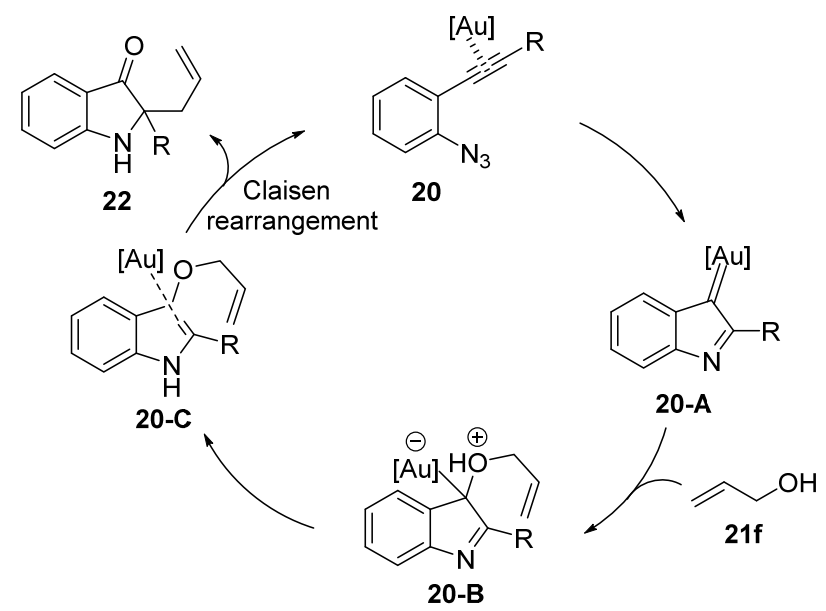

Scheme 14. Plausible mechanism for the formation of indolin-3-ones 22.
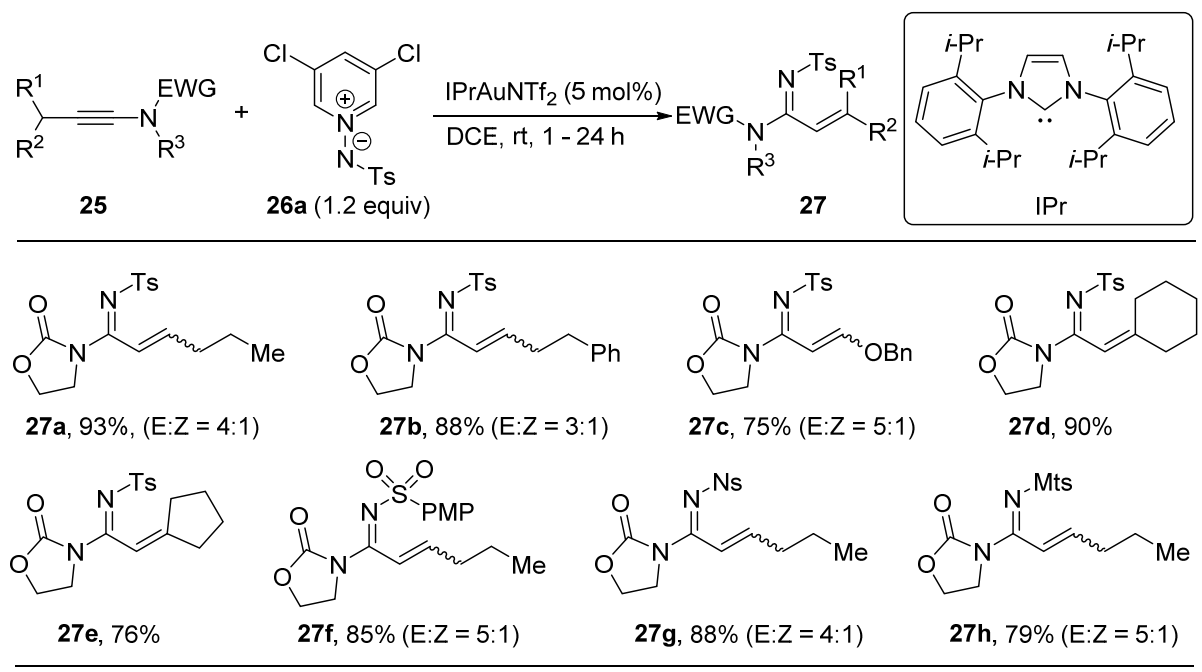

Scheme 15. Synthesis of $\alpha, \beta$-unsaturated amidines 27 employing nitrene-transfer reagents.

\subsection{Synthesis of Quinolines via 1,3-Acetoxy Shift/Cyclization/1,2-Group Shift Sequence}

In 2013, Gagosz and coworkers disclosed a new method for the construction of polysubstituted quinolines through NHC gold-catalyzed intramolecular amination reaction of 2-alkynyl arylazides involving 1,3-acetoxy shift/cyclization/1,2-group shift sequence [87]. The mode of 2-alkynyl arylazides 28 in the presence of $5 \mathrm{~mol} \%$ of IAdAuNTf $f_{2}$ facilely offered the breadth of polysubstituted quinolones 29 in $81 \%-99 \%$ isolated yields with various substrates (Scheme 16). This method worked efficiently for various 2-alkynyl arylazides containing both electron-donating and -withdrawing groups on the phenyl ring, and the resulting products were solely obtained. Notably, a variety of functional groups located at various positions of the aryl group were perfectly tolerated, including alkyl, halogen, ester, and $\mathrm{CF}_{3}$. 


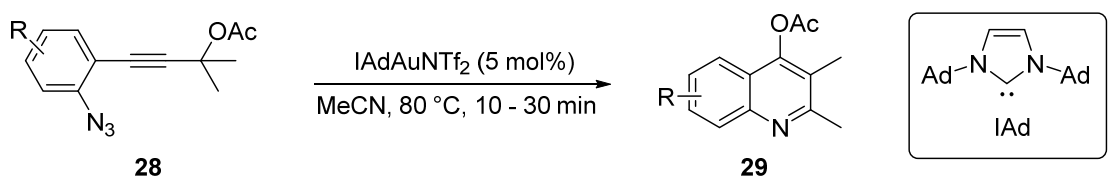

28

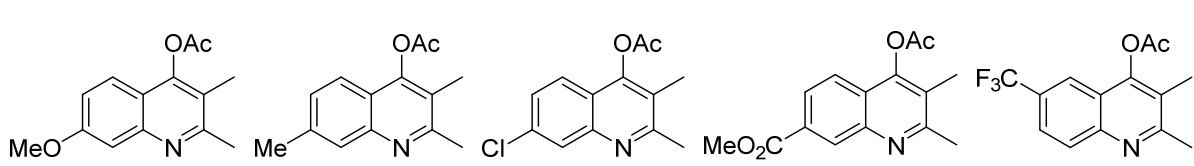

29a, $81 \% \quad 29$ b, $99 \% \quad 29$ c, $88 \% \quad 29$ d, $87 \% \quad 29$ e, $88 \%$

Scheme 16. Synthesis of quinolines 29. Ad = adamantanyl.

Furthermore, this transformation was also extended smoothly to the substrates $\mathbf{3 0}$ bearing a disubstitution with a cyclic motif at the propargylic position of the substrate (Scheme 17). A series of functional groups such as tosylamide, ether, and ketone group were also tolerated, thus delivering the corresponding fused polycylic quinoline derivatives 31 in $52 \%-96 \%$ isolated yields.

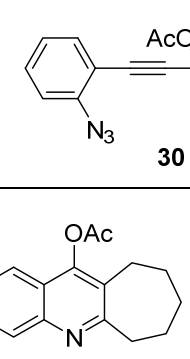

$31 \mathrm{a}, 93 \%$ $\frac{\text { IAdAuNTf }}{\text { MeCN, } 80^{\circ} \mathrm{C}, 10-30 \mathrm{~min}}$

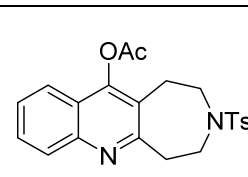

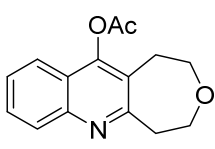

31c, $96 \%$

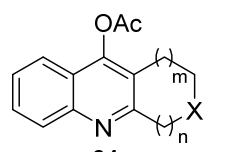

31

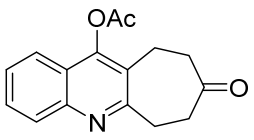

$31 d, 84 \%$
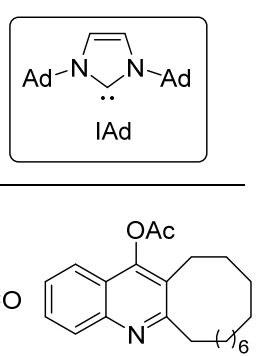

31e, $71 \%$

Scheme 17. Synthesis of fused polycylic quinoline derivatives 31.

On the basis of the experimental observations, a plausible mechanism for this catalytic reaction was presented (Scheme 18). A 1,3-acetoxy shift [88,89] readily occurred, upon treatment with a NHC gold catalyst, to form allenes 28-A, which were attacked preferably by the nitrogen of azide, after extrusion of $\mathrm{N}_{2}$, to easily produce the gold carbenes 28-B. Subsequent 1,2-shift of methyl successfully took place and regeneration of the catalyst delivered smoothly the quinolones 29 via the cationic intermediates 28-C.

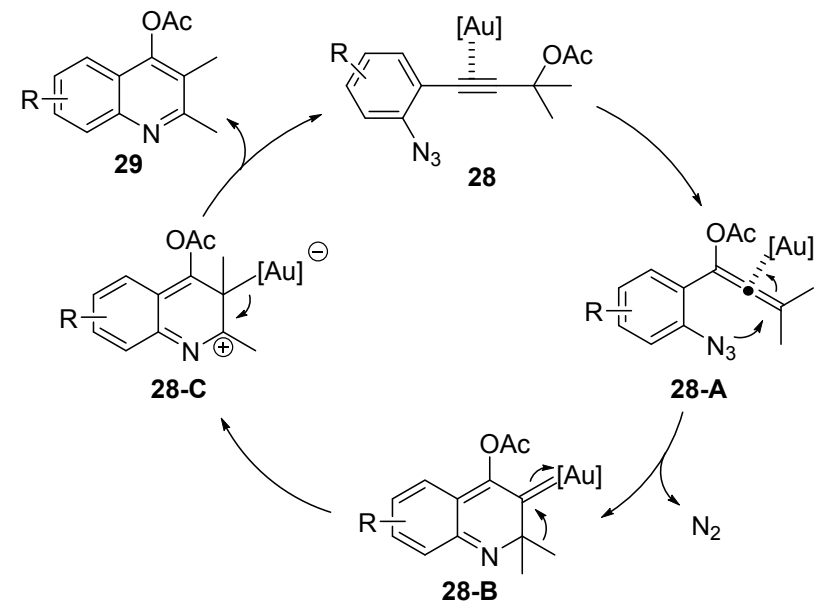

Scheme 18. Proposed mechanism for the formation of quinolines 29. 


\subsection{Synthesis of Pyrroloindolone Derivatives Involving Saucy-Marbet Rearrangement}

In 2015, Gong and coworkers provided a powerful and practical tool for the step-economical synthesis of pyrroloindolone derivatives from the 2-alkynyl arylazides and alkynols [90]. Note that optically pure alkynol substrates could be facilely converted into the chiral pyrroloindolone derivatives with two stereogenic centers, including a quaternary one, albeit with a slightly decreased enantiomeric excesses. It was found that the procedure of 2-alkynyl arylazides 32 with 20 equivalent of alkynols 33 afforded successfully a wealth of pyrroloindolone derivatives 34 with a wide range of structural diversity with [IPrAuNCMe]SbF 6 (10 mol\%) as the catalyst (Scheme 19). Besides an $n$-pentyl group, cycloalkyl, phenyl groups, and $\mathrm{N}$-Boc protected indole were also readily tolerated, leading to the efficient formation of products. Moreover, this tandem reaction also worked well for 2-alkynyl arylazides bearing the substituents with a different electronic nature on the $\mathrm{R}^{1}$. A variety of alkynols were further screened and the expected products were exclusively obtained.
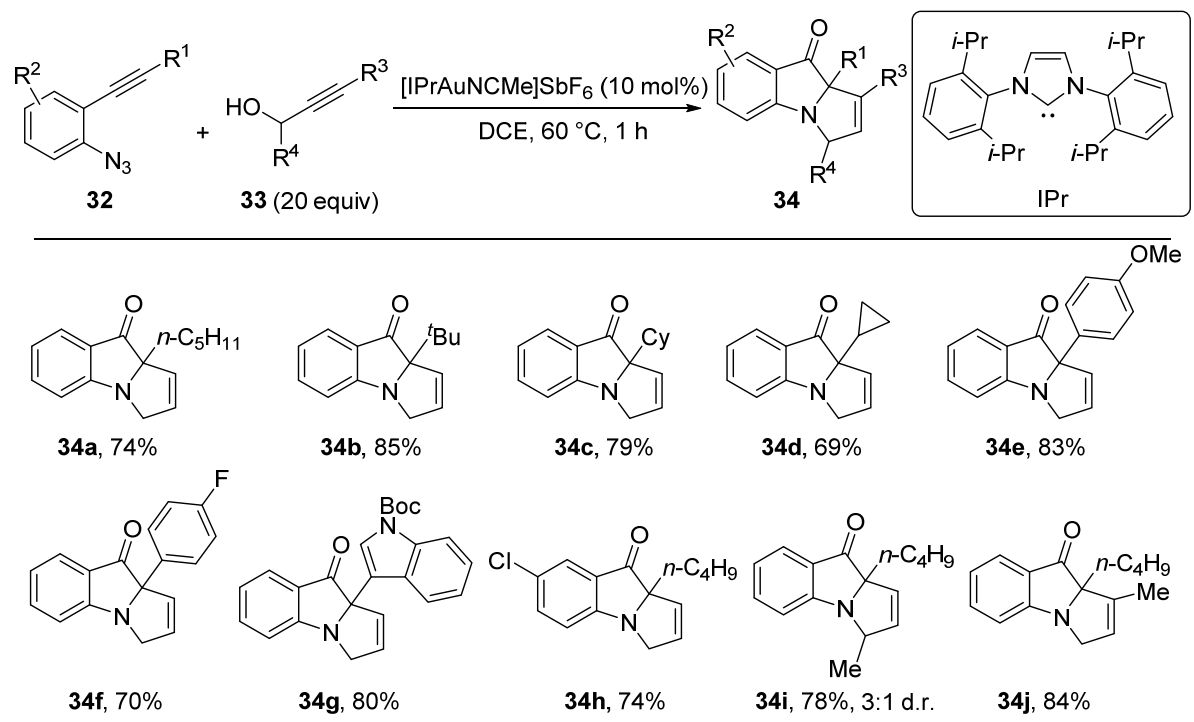

Scheme 19. Synthesis of pyrroloindolone derivatives 34 utilizing Saucy-Marbet rearrangement.

Furthermore, this catalytic reaction could also be successfully extended to optically pure (S)-3-butyn-2-ol 36a, leading to the corresponding chiral pyrroloindolone derivatives 37 (Scheme 20). Importantly, this protocol proceeded with efficient chirality transfer albeit with a slightly decreased enantiomeric excesses.

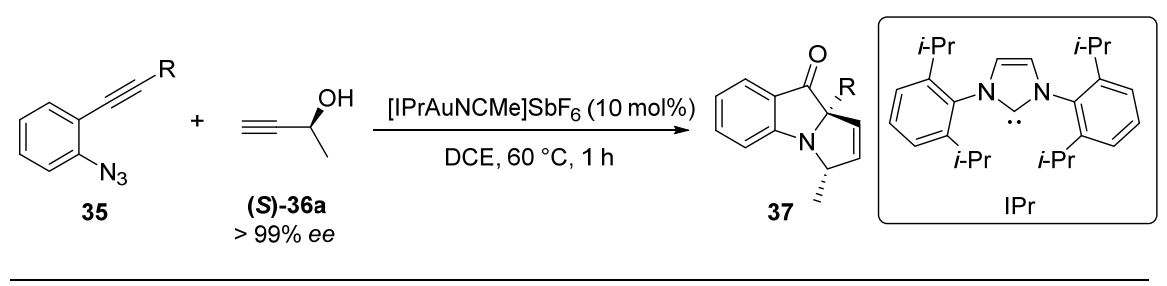<smiles>CCC1(CC)C(=O)c2ccccc2N1C</smiles>

$37 \mathrm{a}$, yield $=78 \%$ d.r. $=3: 1$ $e e=97 \%, 91 \%$

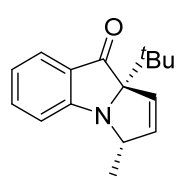

$37 \mathrm{~b}$, yield $=60 \%$ d.r. $=1.2: 1$ ee $=95 \%, 88 \%$

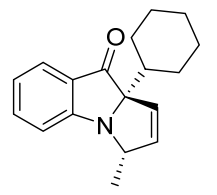

$37 \mathrm{c}$, yield $=56 \%$

d.r. $=3.3: 1$ $e e=98 \%, 95 \%$

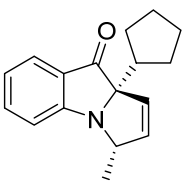

$37 \mathrm{~d}$, yield $=62 \%$ d.r. $=2: 1$ ee $=97 \%, 91 \%$

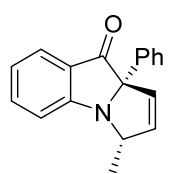

37e, yield $=53 \%$

d.r. $=2.4: 1$ $e e=97 \%, 91 \%$

Scheme 20. Synthesis of chiral pyrroloindolone derivatives 37. 
Gong et al. gave a plausible mechanism for the formation of pyrroloindolone derivatives 34 (Scheme 21). Firstly, intramolecular nucleophilic addition of the azide onto the NHC gold-activated species readily occurred, thus forming the $\alpha$-imino gold carbenes 32-A, which were trapped quickly by an intermolecular $\mathrm{O}-\mathrm{H}$ insertion to generate the 3-alkynyloxyindoles 32-B. Subsequent Saucy-Marbet rearrangement uniquely took place to deliver smoothly the allenes 32-C [91], followed by an intramolecular hydroamination reaction, catalyzed by the same NHC gold complex [92-97], to yield the final pyrroloindolone derivatives 34 .

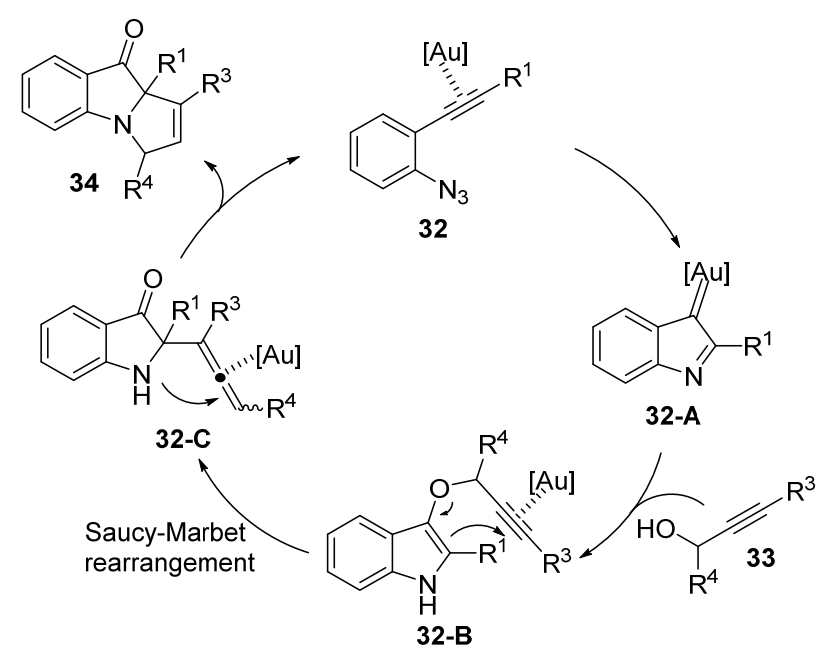

Scheme 21. Mechanistic proposal for the formation of pyrroloindolone derivatives 34 .

\subsection{Synthesis of 2-Aminoindoles and 3-Amino- $\beta$-Carbolines}

In 2015, Ye and coworkers reported a new procedure for the synthesis of 2-aminoindoles and 3-amino- $\beta$-carbolines involving the $\alpha$-imino gold carbenes generated via NHC gold-catalyzed intermolecular amination reaction of activated alkynes and azide [98]. In the presence of $5 \mathrm{~mol} \%$ of $\operatorname{IPrAuNTf}_{2}$, the type of activated alkynes 38 with 2 equivalent of azide 39a easily delivered the bulk of 2-aminoindoles 40 (Scheme 22). The substrates bearing both electron-donating and electron-withdrawing groups on the aromatic ring proceeded smoothly to afford the corresponding products in $77 \%-89 \%$ isolated yields.

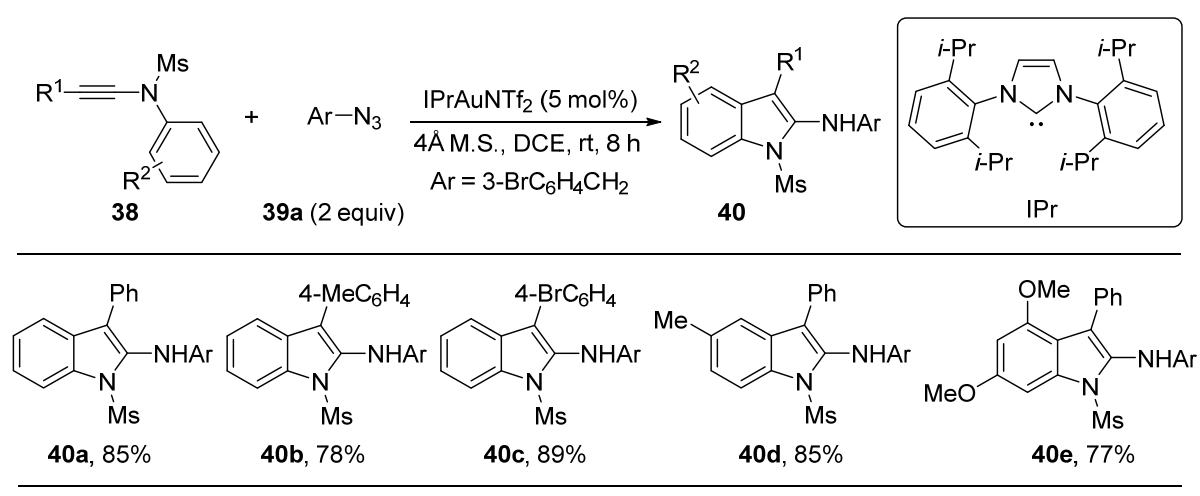

Scheme 22. Synthesis of 2-aminoindoles 40. M.S. = molecular sieves.

Besides 3-bromobenzyl azide, this catalytic reaction also underwent efficiently with indolyl azide 42a, leading to the 3 -amino- $\beta$-carbolines 43 instead of the previous 2 -aminoindoles (Scheme 23 ). This was presumably attributed to the stronger nucleophilic capability of indolyl part than the aryl group on nitrogen of activated alkynes. 


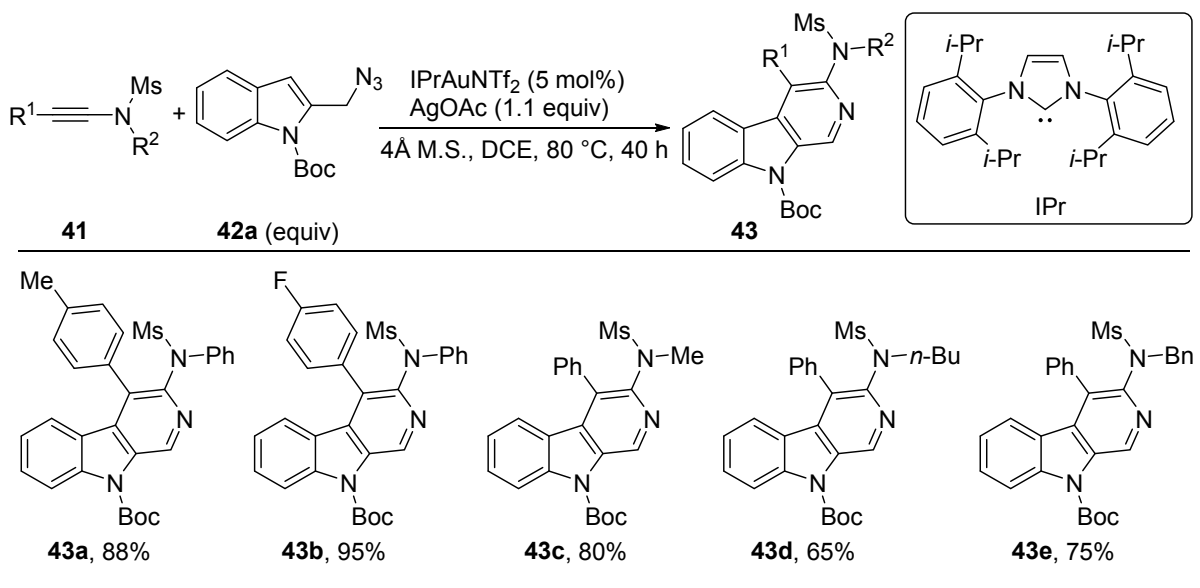

Scheme 23. Synthesis of 3-amino- $\beta$-carbolines 43. M.S. = molecular sieves.

\subsection{Synthesis of 2-Aminopyrroles through Aza-Nazarov Cyclization}

Following this work, the same group developed a novel mode of NHC gold-catalyzed intermolecular alkyne amination-initiated aza-Nazarov cyclization when enynes replaced ordinary alkynes as the substrates [99]. Enynes 44 with 3 equivalent of 3-bromobenzyl azide 45 a could be converted smoothly into the breadth of 2-aminopyrroles 46 by using $\operatorname{IPrAuNTf}_{2}(5 \mathrm{~mol} \%$ ) as the catalyst (Scheme 24$)$. A variety of enynes with aromatic or aliphatic substituents at the $\alpha$ or $\beta$ position were further examined, thus giving the corresponding products. Varying the substituents on the nitrogen of enynes, such as ${ }^{n} \mathrm{Bu}$ and cyclopropyl, were also compatible with this transformation, and providing the desired products in $65 \%-72 \%$ isolated yields.

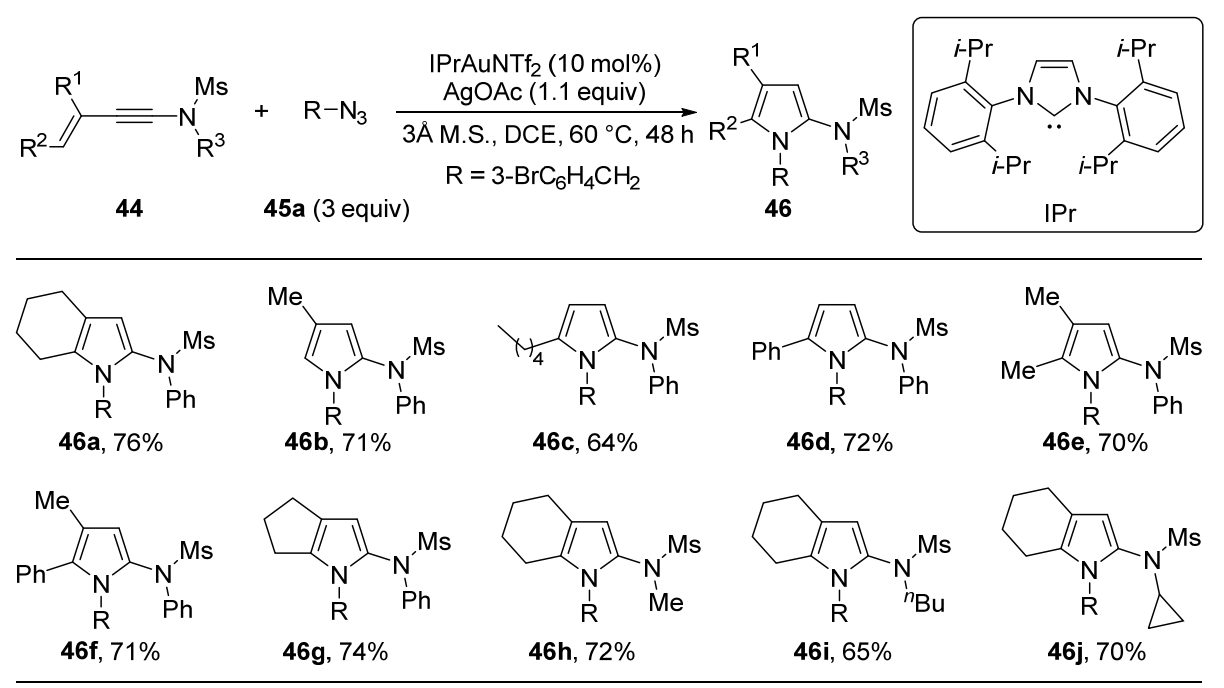

Scheme 24. Synthesis of 2-Aminopyrroles 46 via aza-Nazarov cyclization. M.S. = molecular sieves.

\section{NHC Gold-Catalyzed Alkyne Cycloaddition}

\subsection{Synthesis of 2-Aminonaphthalenes Involving [4+2] Cycloadditions}

In 2012, Liu and coworkers discovered a protocol for the NHC gold-catalyzed [4+2] cycloaddition reaction of enynes with alkenes, leading to various 2-aminonaphthalenes [100]. However, the relevant gold-catalyzed intermolecular reactions of alkynes with alkenes had seldom been explored [101-108]. In this work, initial attack of external alkene on the [ $\left.\mathrm{Au}^{\mathrm{I}}\right]$-ligated $\mathrm{C}-\mathrm{C}$ triple bond of enyne formed cyclopropyl gold carbene, which was then trapped by the tethered phenyl group. In the presence of $5 \mathrm{~mol} \%$ of $\mathrm{IPrAuCl}$ and $5 \mathrm{~mol} \%$ of $\mathrm{AgNTf}_{2}$, enynes 47 with 2 equivalent of alkenes 48 could be 
transformed successfully into a plethora of cycloadducts $\mathbf{4 9}$ (Scheme 25). The functional groups such as 4-methoxyphenyl and 2-thienyl on the double bond were readily tolerated in this tandem reaction. A variety of substituents (e.g. benzo[d][1,3]dioxole, 4-chlorophenyl, 3-thienyl, and 3-benzofuryl) on the enynes also worked well in the reaction to smoothly yield the desired cycloadduct compounds.

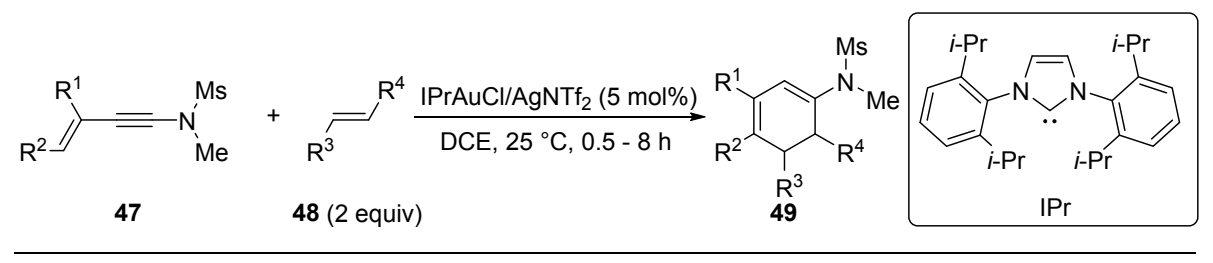<smiles>CN(C)C1=Cc2ccccc2C2OCCCC12</smiles>

$49 a, 61 \%$<smiles>COCC1CC(N(C)C)=Cc2ccc(Cl)cc21</smiles>

$49 e, 81 \%$<smiles>CCOC(=O)c1ccccc1C=C1C(=O)N(C)S(=O)(=O)c2ccccc21</smiles>

49b, $91 \%$<smiles>CCOC(=O)c1sccc1C1CC(N(C)[N+](=O)[O-])=Cc2cccnc21</smiles>
49f, $78 \%$<smiles>CN(C)S(C)(=O)=O</smiles>

$49 c, 82 \%$

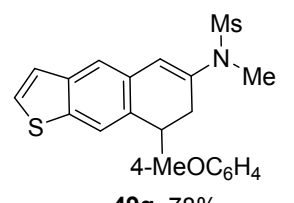

49g, $78 \%$

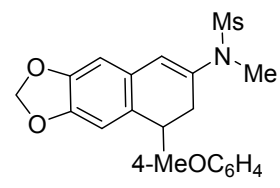

49d, $81 \%$

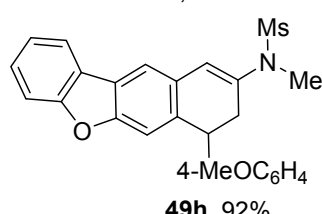

Scheme 25. Synthesis of 2-aminonaphthalenes 49.

\subsection{Synthesis of Benzoxepine Frameworks through [4+3] Cycloaddition}

Following this work, the same group reported a new way for the preparation of seven-membered oxacycles through NHC gold-catalyzed [4+3] cycloaddition of epoxides with arenynamides [109]. It should be noted that the retention of stereochemistry was inspected in the gold-catalyzed ring opening of epoxides. An $\mathrm{S}_{\mathrm{N}}$ 2-type front-side attack of phenyl at the oxiranyl ring was presumably involved in this formal [4+3] cycloaddition. It was found that the procedure of enynes $\mathbf{5 0}$ with 4 equivalent of epoxides $\mathbf{5 1}$ using $\operatorname{IPrAuNTf}_{2}(5 \mathrm{~mol} \%$ ) facilely provided a plethora of cycloadducts $\mathbf{5 2}$ (Scheme 26). Varying substrates bearing amido substituents, including tosyl, mesyl, methyl, phenyl, benzyl, 4-chloro, 4-methoxy, and 2-thienyl, on the ynamides were well compatible with this tandem reaction, thus giving the resulting cycloadducts. In addition, a variety of epoxides were also examined to deliver the desired cycloadduct compounds. It is important to point out that stereochemistry $[110,111]$ was retained for an intermolecular aryl attack at the epoxide.

\subsection{Synthesis of 7-Acylindoles via [3+2] Cycloaddition}

In 2016, Hashmi and coworkers disclosed a new type of NHC gold-catalyzed formal [3+2] cycloaddition reaction of alkynes with anthranils, involving ortho-aryl C-H functionalization, leading to the efficient synthesis of various unprotected 7-acylindoles (Scheme 27) [112]. Anthranils 54 with 1.5 equivalent alkynes 53 could be readily converted into a range of 7-acylindoles 55 in $50-86 \%$ isolated yields with various substrates by utilizing $\mathrm{IPrAuCl} / \mathrm{AgNTf}_{2}(5 \mathrm{~mol} \%)$ as the catalyst. A diverse array of substituents, such as $\mathrm{Ph},{ }^{n} \mathrm{Bu}, \mathrm{Cy}, \mathrm{Me},{ }^{i} \mathrm{Pr}$, and $\mathrm{Bn}$, at the ynamide nitrogen atom were well tolerated during such a one-pot cascade, giving the resulting products. Besides, phenyl- and alkene-substituted anthranils were also suitable substrates for this catalytic reaction. 


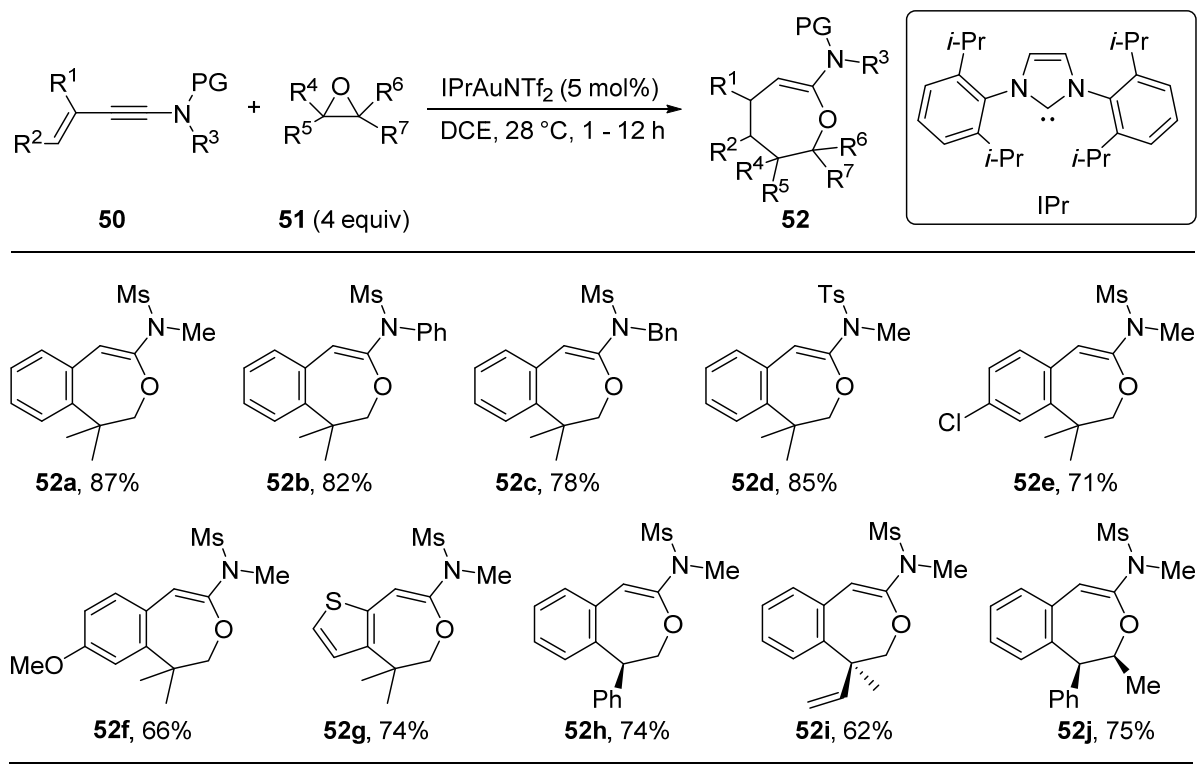

Scheme 26. Synthesis of seven-membered oxacycles 52 .
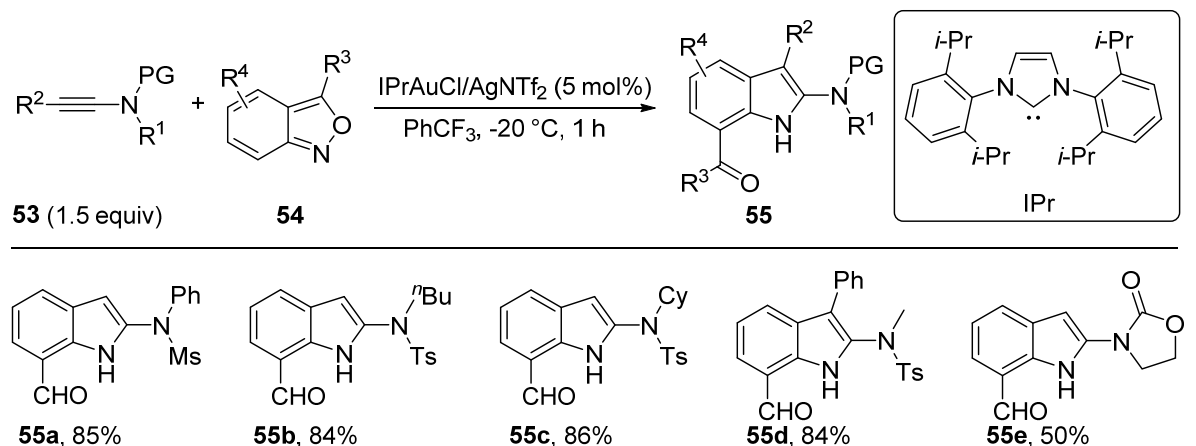

$\begin{array}{lllll}\mathbf{5 5 a}, 85 \% & \mathbf{5 5 b}, 84 \% & \mathbf{5 5 c}, 86 \% & \mathbf{5 5 d}, 84 \% & \mathbf{5 5 e}, 50 \%\end{array}$

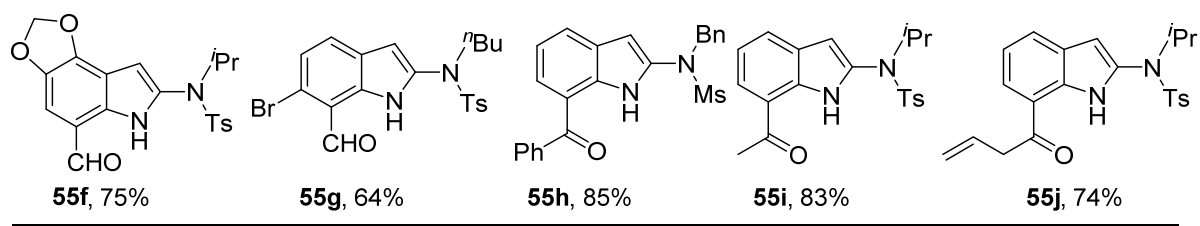

Scheme 27. Synthesis of unprotected 7-acylindoles 55.

The following mechanism was illustrated to explain the formation of 7-acylindoles 55 (Scheme 28). This tandem reaction was triggered by nucleophilic attack of the anthranils 54 to the gold-coordinated activated alkynes 53 to provide the vinyl gold intermediates $53-\mathrm{A}$. Upon $\mathrm{N}-\mathrm{O}$ bond cleavage, $\alpha$-imino gold-carbene intermediates 53-B were then efficiently formed, followed by an intramolecular ortho-aryl $\mathrm{C}-\mathrm{H}$ insertion onto a gold-carbene species, thus giving the resulting 7-acylindoles 55. 


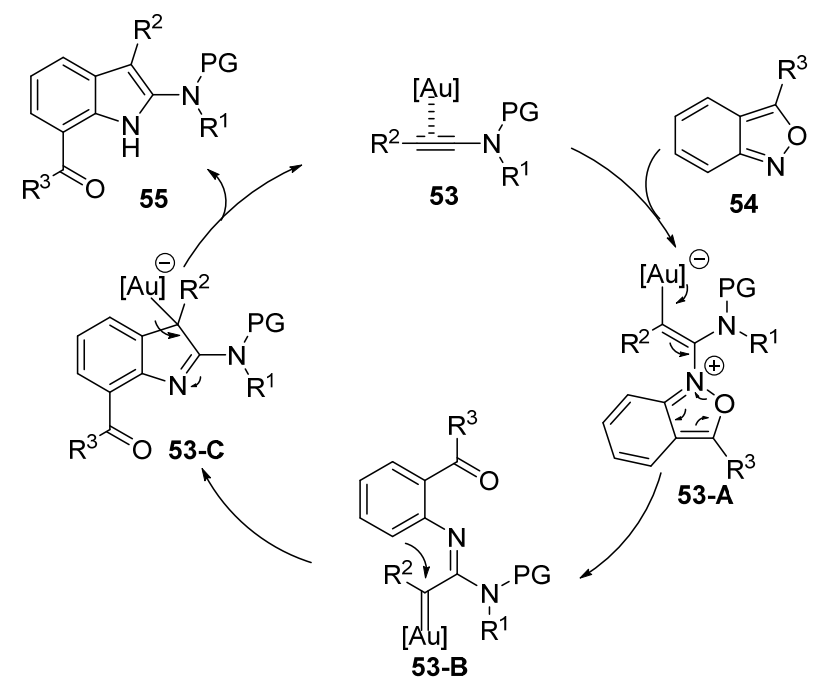

Scheme 28. Proposed mechanism for the formation of unprotected 7-acylindoles 55.

\subsection{Synthesis of Cyclobutenes Involving [2+2] Cycloadditions}

Very recently, Zhang and coworkers described a new mode of NHC gold-catalyzed [2+2] cycloaddition reaction of alkynes with alkene, allowing the facile synthesis of various valuable cyclobutenes [113]. Of note, achieving this cycloaddition reaction was highly challenging due to the fact that alkenes involved in such a tandem sequence were all electronically inactivated. As shown in Scheme 29, the type of chloroalkynes 56 with 3 equivalent of alkenes 57 , utilizing $\operatorname{IPrAuCl}(5 \mathrm{~mol} \%)$ and NaBARF (10 mol\%), offered smoothly a wealth of cyclobutenes 58 in $56-86 \%$ isolated yields. Cyclic alkenes of various other ring sizes were well tolerated. Chloroalkynes terminated with a cyclopropyl group was also a suitable substrate for this transformation. Notably, for the monosubstituted alkenes, the reactions proceeded smoothly to yield the desired products with excellent regioselectivities, which were substantially better than observed in previous protocols [114-116].

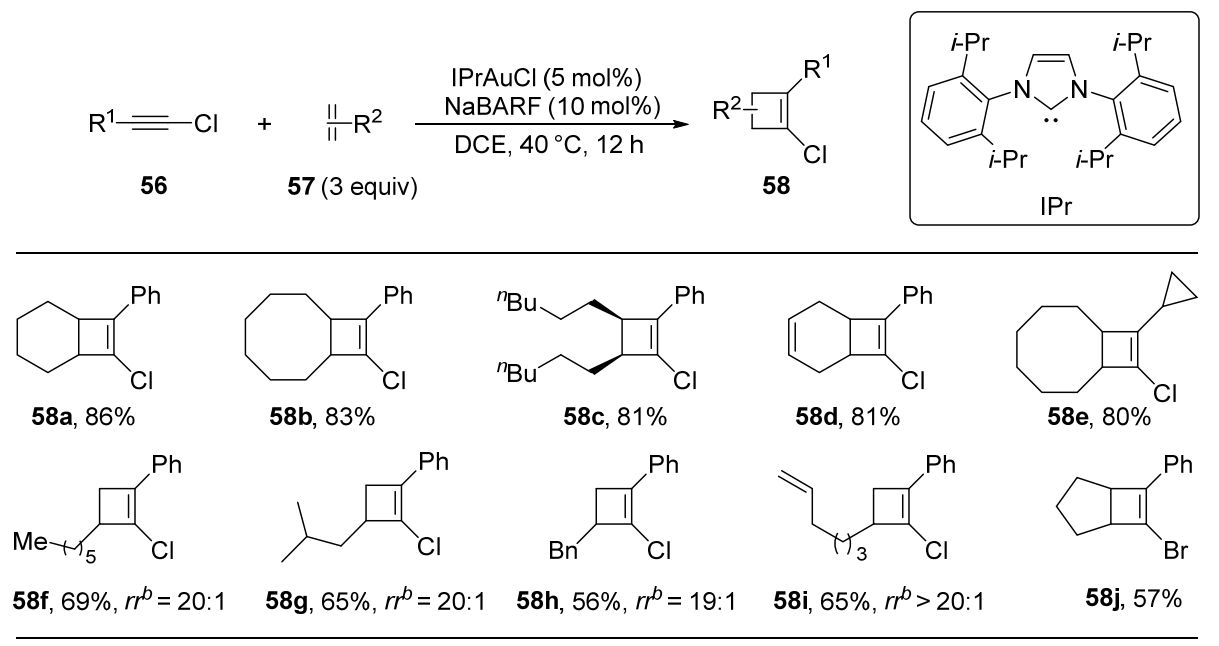

Scheme 29. Synthesis of cyclobutenes 58. NaBARF = sodium tetrakis[3,5-bis(trifluoromethyl)phenyl]borate.

Furthermore, this cascade cyclization was also extended successfully to chloroethynyl phenyl sulfide 59a, giving the expected cyclobutene products 61 in $55-84 \%$ isolated yields (Scheme 30). Compared to the (chloroethynyl)arenes, the chloroethynyl phenyl sulfide could react more efficiently with alkenes and displayed excellent regioselectivities with the treatment of monosubstituted alkenes in general. 


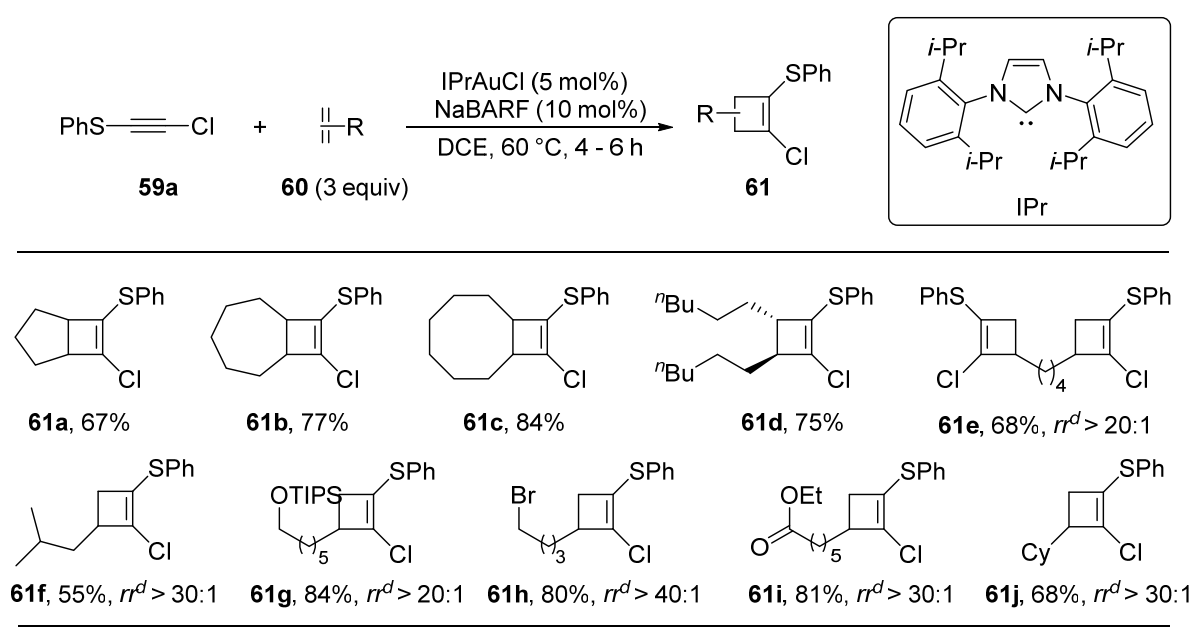

Scheme 30. Synthesis of phenyl sulfide-substituted cyclobutenes $\mathbf{6 1 .}$

\section{Conclusions}

As has been shown in this review, catalytic reactions of alkynes enabled by Au-NHC complexes have experienced rapid development, and more fascinating facets of this approach have been achieved. Arguably, impressive advances have been made towards Au-NHC catalyzed oxidation reactions, amination reactions, and cycloaddition reactions. Of note, these approaches provide efficient access to various structurally complex cyclic molecules-especially the valuable heterocycles in a single synthetic step-and thus make important contributions to synthetic organic chemistry.

Moreover, a detailed understanding of the mechanisms would require more experimental investigations. Many of the reaction mechanisms are based on computational chemistry or indirect evidence. As more data of Au-NHC-catalyzed reactions of alkynes become available, more effort ought to be focused on mechanistic insights, including the role of the electronic and steric properties as the counteranion of the catalyst in catalytic reaction remains to be clearly established.

In the area of chiral Au-NHC complexes, the future will likely hold the bulk of new possibilities as the mechanisms are further elucidated. More catalytic enantioselective version of gold-catalyzed oxidation/amination/cycloaddition of alkynes will be achieved by employing chiral NHC complexes as ligands, leading to a plethora of considerable and available chiral compounds. Furthermore, it is desirable to develop highly active and robust catalysts that can utilize the non-noble metals, such as copper complexes. Consequently, an increasing number of research attention to this realm is anticipated and more reasonable devices will be realized for the facile synthesis of various skeletons by employing highly tunable NHC ligands combined with effective metal complexes in the near future.

Funding: This research was funded by the Top-Notch Talents Program of Henan Agricultural University (30500739).

Conflicts of Interest: The authors declare no conflict of interest.

\section{References}

1. Arduengo, A.J.; Harlow, R.L.; Kline, M. A Stable Crystalline Carbene. J. Am. Chem. Soc. 1991, 113, $363-365$. [CrossRef]

2. Crudden, C.M.; Allen, D.P. Stability and Reactivity of N-Heterocyclic Carbene Complexes. Coord. Chem. Rev. 2004, 248, 2247-2273. [CrossRef]

3. Hopkinson, M.N.; Richter, C.; Schedler, M.; Glorius, F. An Overview of N-Heterocyclic Carbenes. Nature 2014, 510, 485-496. [CrossRef] [PubMed]

4. Kantchev, E.A.B.; O’Brien, C.J.; Organ, M.G. Palladium Complexes of N-Heterocyclic Carbenes as Catalysts for Cross Coupling Reactions-A Synthetic Chemist's Perspective. Angew. Chem. Int. Ed. 2007, 46, 2768-2813. [CrossRef] 
5. Doddi, A.; Peters, M.; Tamm, M. N-Heterocyclic Carbene Adducts of Main Group Elements and Their Use as Ligands in Transition Metal Chemistry. Chem. Rev. 2019, 119, 6994-7112. [CrossRef]

6. Hameury, S.; Frémont, P.; Braunstein, P. Metal Complexes with Oxygen-Functionalized NHC Ligands: Synthesis and Applications. Chem. Soc. Rev. 2017, 46, 632-733. [CrossRef]

7. Zhang, D.; Zi, G. N-Heterocyclic Carbene (NHC) Complexes of Group 4 Transition Metals. Chem. Soc. Rev. 2015, 44, 1898-1921. [CrossRef]

8. Velazquez, H.D.; Verpoort, F. N-Heterocyclic Carbene Transition Metal Complexes for Catalysis in Aqueous Media. Chem. Soc. Rev. 2012, 41, 7032-7060. [CrossRef]

9. Fortman, G.C.; Nolan, S.P. N-Heterocyclic Carbene (NHC) Ligands and Palladium in Homogeneous Cross-Coupling Catalysis: A Perfect Union. Chem. Soc. Rev. 2011, 40, 5151-5169. [CrossRef]

10. Lin, J.C.Y.; Huang, R.T.W.; Lee, C.S.; Bhattacharyya, A.; Hwang, W.S.; Lin, I.J.B. Coinage Metal-N-Heterocyclic Carbene (NHC) Complexes. Chem. Rev. 2009, 109, 3561-3598. [CrossRef]

11. Díez-González, S.; Marion, N.; Nolan, S.P. N-Heterocyclic Carbenes in Late Transition Metal Catalysis. Chem. Rev. 2009, 109, 3612-3676. [CrossRef] [PubMed]

12. Garrison, J.C.; Youngs, W.J. Ag(I) N-Heterocyclic Carbene (NHC) Complexes: Synthesis, Structure, and Application. Chem. Rev. 2005, 105, 3978-4008. [CrossRef] [PubMed]

13. Herrmann, W.A.; Köcher, C. N-Heterocyclic Carbenes. Angew. Chem. Int. Ed. 1997, 36, 2162-2187. [CrossRef]

14. Bourissou, D.; Guerret, O.; Gabbaï, F.P.; Bertrand, G. Stable Carbenes. Chem. Rev. 2000, 100, 39-92. [CrossRef] [PubMed]

15. Hahn, F.E.; Jahnke, M.C. Heterocyclic carbenes: Synthesis and Coordination Chemistry. Angew. Chem. Int. Ed. 2008, 47, 3122-3172. [CrossRef]

16. De Fremont, P.; Marion, N.; Nolan, S.P. Carbenes: Synthesis, Properties, and Organometallic Chemistry. Coord. Chem. Rev. 2009, 253, 862-892. [CrossRef]

17. Herrmann, W.A. N-Heterocyclic Carbenes: A New Concept in Organometallic Catalysis. Angew. Chem. Int. Ed. 2002, 41, 1290-1309. [CrossRef]

18. Mercs, L.; Albrecht, M. Beyond Catalysis: N-Heterocyclic Carbene Complexes as Components for Medicinal, Luminescent, and Functional Materials Applications. Chem. Soc. Rev. 2010, 39, 1903-1912. [CrossRef]

19. Oisaki, K.; Li, Q.; Furukawa, H.; Czaja, A.U.; Yaghi, O.M. A Metal-Organic Framework with Covalently Bound Organometallic Complexes. J. Am. Chem. Soc. 2010, 132, 9262-9264. [CrossRef]

20. Lee, K.M.; Lee, C.K.; Lin, I.J.B. A Facile Synthesis of Unusual Liquid-Crystalline Gold(I) Dicarbene Compounds. Angew. Chem. Int. Ed. 1997, 36, 1850-1852. [CrossRef]

21. Boydston, A.J.; Williams, K.A.; Bielawski, C.W. A Modular Approach to Main-Chain Organometallic Polymers. J. Am. Chem. Soc. 2005, 127, 12496-12497. [CrossRef] [PubMed]

22. Visbal, R.; Gimeno, M.C. N-Heterocyclic Carbene Metal Complexes: Photoluminescence and Applications. Chem. Soc. Rev. 2014, 43, 3551-3574. [CrossRef] [PubMed]

23. Enders, D.; Niemeier, O.; Henseler, A. Organocatalysis by N-Heterocyclic Carbenes. Chem. Rev. 2007, 107, 5606-5655. [CrossRef] [PubMed]

24. Marion, N.; Díez-Gonzalez, S.; Nolan, S.P. N-Heterocyclic Carbenes as Organocatalysts. Angew. Chem. Int. Ed. 2007, 46, 2988-3000. [CrossRef]

25. Hindi, K.M.; Panzner, M.J.; Tessier, C.A.; Cannon, C.L.; Youngs, W.J. The Medicinal Applications of Imidazolium Carbenemetal Complexes. Chem. Rev. 2009, 109, 3859-3884. [CrossRef]

26. Raubenheimer, H.G.; Cronje, S. Carbene Complexes of Gold: Preparation, Medical Application and Bonding. Chem. Soc. Rev. 2008, 37, 1998-2011. [CrossRef]

27. Liu, W.; Gust, R. Metal N-Heterocyclic Carbene Complexes as Potential Antitumor Metallodrugs. Chem. Soc. Rev. 2013, 42, 755-773. [CrossRef]

28. Liu, W.; Gust, R. Update on Metal N-Heterocyclic Carbene Complexes as Potential Anti-Tumor Metallodrugs. Coord. Chem. Rev. 2016, 329, 191-213. [CrossRef]

29. Nelson, D.J.; Nolan, S.P. Quantifying and Understanding the Electronic Properties of N-Heterocyclic Carbenes. Chem. Soc. Rev. 2013, 42, 6723-6753. [CrossRef]

30. Peris, E. Smart N-Heterocyclic Carbene Ligands in Catalysis. Chem. Rev. 2018, 118, 9988-10031. [CrossRef]

31. Peris, E.; Crabtree, R.H. Recent Homogeneous Catalytic Applications of Chelate and Pincer N-Heterocyclic Carbenes. Coord. Chem. Rev. 2004, 248, 2239-2246. [CrossRef] 
32. Scholl, M.; Ding, S.; Lee, C.W.; Grubbs, R.H. Synthesis and Activity of A New Generation of Ruthenium-Based Olefin Metathesis Catalysts Coordinated with 1, 3-Dimesity-4, 5-Dihydroimidazol-2-Ylidene Ligands. Org. Lett. 1999, 1, 953-956. [CrossRef]

33. Scholl, M.; Trnka, T.M.; Morgan, J.P.; Grubbs, R.H. Increased Ring Closing Metathesis Activity of Ruthenium-Based Olefin Metathesis Catalysts Coordinated with Imidazolin-2-Ylidene Ligands. Tetrahedron Lett. 1999, 40, 2247-2250. [CrossRef]

34. Sanford, M.S.; Love, J.A.; Grubbs, R.H. Mechanism and Activity of Ruthenium Olefin Metathesis Catalysts. J. Am. Chem. Soc. 2001, 123, 6543-6554. [CrossRef] [PubMed]

35. Samojlowicz, C.; Bieniek, M.; Grela, K. Ruthenium-Based Olefin Metathesis Catalysts Bearing N-Heterocyclic Carbene Ligands. Chem. Rev. 2009, 109, 3708-3742. [CrossRef] [PubMed]

36. Vougioukalakis, G.C.; Grubbs, R.H. Ruthenium-Based Heterocyclic Carbene-Coordinated Olefin Metathesis Catalysts. Chem. Rev. 2010, 110, 1746-1787. [CrossRef]

37. Zhang, C.; Huang, J.; Trudell, M.L.; Nolan, S.P. Palladium-Imidazol-2-Ylidene Complexes as Catalysts for Facile and Efficient Suzuki Cross-Coupling Reactions of Aryl Chlorides with Arylboronic Acids. J. Org. Chem. 1999, 64, 3804-3805. [CrossRef]

38. Eckhardt, M.; Fu, G.C. The First Applications of Carbene Ligands in Cross-Couplings of Alkyl Electrophiles: Sonogashira Reactions of Unactivated Alkyl Bromides and Iodides. J. Am. Chem. Soc. 2003, 125, 13642-13643. [CrossRef]

39. Frisch, A.C.; Rataboul, F.; Zapf, A.; Beller, M. First Kumada Reaction of Alkyl Chlorides Using N-Heterocyclic Carbene/Palladium Catalyst Systems. J. Organomet. Chem. 2003, 687, 403-409. [CrossRef]

40. Schuster, O.; Yang, L.; Raubenheimer, H.G.; Albrecht, M. Beyond Conventional N-Heterocyclic Carbenes: Abnormal, Remote, and other Classes of NHC Ligands with Reduced Heteroatom Stabilization. Chem. Rev. 2009, 109, 3445-3478. [CrossRef]

41. Shen, W.-B.; Tang, X.-T. Recent Advances in Catalytic Asymmetric Intermolecular Oxidation of Alkyne. Org. Biomol. Chem. 2019, 17, 7106-7113. [CrossRef] [PubMed]

42. Asiri, A.M.; Hashmi, A.S.K. Gold-Catalysed Reactions of Diynes. Chem. Soc. Rev. 2016, 45, 4471-4503. [CrossRef] [PubMed]

43. Zheng, Z.; Wang, Z.; Wang, Y.; Zhang, L. Au-Catalysed Oxidative Cyclisation. Chem. Soc. Rev. 2016, 45, 4448-4458. [CrossRef] [PubMed]

44. Liu, L.; Zhang, J. Gold-Catalyzed Transformations of $\alpha$-Diazocarbonyl Compounds: Selectivity and Diversity. Chem. Soc. Rev. 2016, 45, 506-516. [CrossRef] [PubMed]

45. Huple, D.B.; Ghorpade, S.; Liu, R.-S. Recent Advances in Gold-Catalyzed N- and O-Functionalizations of Alkynes with Nitrones, Nitroso, Nitro and Nitroxy Species. Adv. Synth. Catal. 2016, 358, 1348-1367. [CrossRef]

46. Qian, D.; Zhang, J. Gold-Catalyzed Cyclopropanation Reactions Using A Carbenoid Precursor Toolbox. Chem. Soc. Rev. 2015, 44, 677-698. [CrossRef]

47. Dorel, R.; Echavarren, A.M. Gold (I)-Catalyzed Activation of Alkynes for the Construction of Molecular Complexity. Chem. Rev. 2015, 115, 9028-9072. [CrossRef]

48. Wang, Y.; Muratore, M.E.; Echavarren, A.M. Gold Carbene or Carbenoid: Is There A Difference? Chem. Eur. J. 2015, 21, 7332-7339. [CrossRef]

49. Yeom, H.-S.; Shin, S. Catalytic Access to $\alpha$-Oxo Gold Carbenes by N-O Bond Oxidants. Acc. Chem. Res. 2014, 47, 966-977. [CrossRef]

50. Fensterbank, L.; Malacria, M. Molecular Complexity from Polyunsaturated Substrates: The Gold Catalysis Approach. Acc. Chem. Res. 2014, 47, 953-965. [CrossRef]

51. Obradors, C.; Echavarren, A.M. Gold-Catalyzed Rearrangements and Beyond. Acc. Chem. Res. 2014, 47, 902-912. [CrossRef] [PubMed]

52. Zhang, L. A Non-Diazo Approach to $\alpha$-Oxo Gold Carbenes via Gold-Catalyzed Alkyne Oxidation. Acc. Chem. Res. 2014, 47, 877-888. [CrossRef] [PubMed]

53. Hashmi, A.S.K. Dual Gold Catalysis. Acc. Chem. Res. 2014, 47, 864-876. [CrossRef] [PubMed]

54. Pflasterer, D.; Hashmi, A.S.K. Gold Catalysis in Total Synthesis-Recent Achievements. Chem. Soc. Rev. 2016, 45, 1331-1367. [CrossRef] [PubMed]

55. Rudolph, M.; Hashmi, A.S.K. Gold Catalysis in Total Synthesis-An Update. Chem. Soc. Rev. 2012, 41, 2448-2462. [CrossRef] [PubMed] 
56. Hashmi, A.S.K.; Rudolph, M. Gold Catalysis in Total Synthesis. Chem. Soc. Rev. 2008, 37, 1766-1775. [CrossRef]

57. Rode, N.; Marinelli, F.; Arcadi, A.; Adak, T.; Rudolph, M.; Rominger, F.; Hashmi, A.S.K. Sequential Gold-Catalyzed Carbene Transfer/Ring Closure: Oxidative Cyclization of $\beta$-(2-Alkynylphenyl)- $\alpha, \beta$-ynones to Indenofuranones. Adv. Synth. Catal. 2018, 360, 4790-4794. [CrossRef]

58. Chen, H.; Zhang, L. A Desulfonylative Approach in Oxidative Gold Catalysis: Regiospecific Access to Donor-Substituted Acyl Gold Carbenes. Angew. Chem. Int. Ed. 2015, 54, 11775-11779. [CrossRef]

59. Kumar, A.; Singh, C.; Tinnermann, H.; Huynh, H.V. Gold(I) and Gold(III) Complexes of Expanded-Ring N-Heterocyclic Carbenes: Structure, Reactivity, and Catalytic Applications. Organometallics 2020, 39, 172-181. [CrossRef]

60. Gonell, S.; Poyatos, M.; Peris, E. Triphenylene-Based Tris(N-Heterocyclic Carbene) Ligand: Unexpected Catalytic Benefits. Angew. Chem. Int. Ed. 2013, 52, 7009-7013. [CrossRef]

61. Zeng, X.; Frey, G.D.; Kinjo, R.; Donnadieu, B.; Bertrand, G. Synthesis of a Simplified Version of Stable Bulky and Rigid Cyclic (Alkyl)(amino)carbenes, and Catalytic Activity of the Ensuing Gold(I) Complex in the Three-Component Preparation of 1,2-Dihydroquinoline Derivatives. J. Am. Chem. Soc. 2009, 131, 8690-8696. [CrossRef] [PubMed]

62. Dash, C.; Shaikh, M.M.; Butcher, R.J.; Ghosh, P. Highly Convenient Regioselective Intermolecular Hydroamination of Alkynes Yielding Ketimines Catalyzed by Gold(I) Complexes of 1,2,4-triazole Based N-heterocyclic Carbenes. Inorg. Chem. 2010, 49, 4972-4983. [CrossRef] [PubMed]

63. García-Fernández, P.D.; Izquierdo, C.; Iglesias-Sigüenza, J.; Díez, E.; Fernández, R.; Lassaletta, J.M. AuI-Catalyzed Haloalkynylation of Alkenes. Chem. Eur. J. 2020, 26, 629-633. [CrossRef] [PubMed]

64. Schulz, J.; Jašíková, L.; Škríba, A.; Roithová, J. Role of Gold(I) $\alpha$-Oxo Carbenes in the Oxidation Reactions of Alkynes Catalyzed by Gold(I) Complexes. J. Am. Chem. Soc. 2014, 136, 11513-11523. [CrossRef] [PubMed]

65. Wang, J.; Cao, X.; Lv, S.; Zhang, C.; Xu, S.; Shi, M.; Zhang, J. Synthesis and Structures of Gold and Copper Carbene Intermediates in Catalytic Amination of Alkynes. Nat. Commun. 2017, 8, 14625-14634. [CrossRef] [PubMed]

66. Orbe, M.E.; Amenós, L.; Kirillova, M.S.; Wang, Y.; López-Carrillo, V.; Maseras, F.; Echavarren, A.M. Cyclobutene vs. 1,3-Diene Formation in the Gold-Catalyzed Reaction of Alkynes with Alkenes: The Complete Mechanistic Picture. J. Am. Chem. Soc. 2017, 139, 10302-10311. [CrossRef]

67. Li, J.; Ji, K.; Zheng, R.; Nelsona, J.; Zhang, L. Expanding the Horizon of Intermolecular Trapping of in situ Generated $\alpha$-Oxo Gold Carbenes: Efficient Oxidative Union of Allylic Sulfides and Terminal Alkynes via C-C Bond Formation. Chem. Commun. 2014, 50, 4130-4133. [CrossRef]

68. Tian, X.; Song, L.; Farshadfar, K.; Rudolph, M.; Rominger, F.; Oeser, T.; Ariafard, A.; Hashmi, A.S.K. Acyl Migration versus Epoxidation in Gold Catalysis: Facile, Switchable, and Atom-Economic Synthesis of Acylindoles and Quinoline Derivatives. Angew. Chem. Int. Ed. 2020, 59, 471-478. [CrossRef]

69. Witham, C.A.; Mauleón, P.; Shapiro, N.D.; Sherry, B.D.; Toste, F.D. Gold(I)-Catalyzed Oxidative Rearrangements. J. Am. Chem. Soc. 2007, 129, 5838-5839. [CrossRef]

70. Li, G.; Zhang, L. Gold-Catalyzed Intramolecular Redox Reaction of Sulfinyl Alkynes: Efficient Generation of $\alpha$-Oxo Gold Carbenoids and Application in Insertion into R-CO Bonds. Angew. Chem. Int. Ed. 2007, 46, 5156-5159. [CrossRef]

71. Pellicciari, R.; Fringuelli, R.; Ceccherelli, P.; Sisani, E. $\beta$-Keto Esters from the Rhodium(II) Acetate Catalysed Conversion of $\alpha$-Diazo- $\beta$-Hydroxy Esters. J. Chem. Soc. Chem. Commun. 1979, 959-960. [CrossRef]

72. Holmquist, C.R.; Roskamp, E.J. A Selective Method for the Direct Conversion of Aldehydes into.Beta.-Keto Esters with Ethyl Diazoacetate Catalyzed by Tin(II) Chloride. J. Org. Chem. 1989, 54, 3258-3260. [CrossRef]

73. Kanemasa, S.; Kanai, T.; Araki, T.; Wada, E. Lewis Acid-Catalyzed Reactions of Ethyl Diazoacetate with Aldehydes. Synthesis of $\alpha$-Formyl Esters by A Sequence of Aldol Reaction and 1,2-Nucleophilic Rearrangement. Tetrahedron Lett. 1999, 40, 5055-5058. [CrossRef]

74. Liao, M.; Wang, J. CuSO 4 -Catalyzed Diazo Decomposition in Water: A Practical Synthesis of $\beta$-Keto Esters. Tetrahedron Lett. 2006, 47, 8859-8861. [CrossRef]

75. Xiao, F.; Wang, J. 1,2-Migration in Rhodium(II) Carbene Transfer Reaction: Remarkable Steric Effect on Migratory Aptitude. J. Org. Chem. 2006, 71, 5789-5791. [CrossRef] 
76. Benito-Garagorri, D.; Wiedermann, J.; Pollak, M.; Mereiter, K.; Kirchner, K. Iron(II) Complexes Bearing Tridentate PNP Pincer-Type Ligands as Catalysts for the Selective Formation of 3-Hydroxyacrylates from Aromatic Aldehydes and Ethyldiazoacetate. Organometallics 2007, 26, 217-222. [CrossRef]

77. Lu, B.; Li, C.; Zhang, L. Gold-Catalyzed Highly Regioselective Oxidation of C-C Triple Bonds without Acid Additives: Propargyl Moieties as Masked $\alpha, \beta$-Unsaturated Carbonyls. J. Am. Chem. Soc. 2010, 132, 14070-14072. [CrossRef]

78. Bhunia, S.; Ghorpade, S.; Huple, D.B.; Liu, R.-S. Gold-Catalyzed Oxidative Cyclizations of cis-3-En-1-Ynes to Form Cyclopentenone Derivatives. Angew. Chem. Int. Ed. 2012, 51, 2939-2942. [CrossRef]

79. Robins, M.J.; Guo, Z.; Samano, M.C.; Wnuk, S.F. Biomimetic Simulation of Free Radical-Initiated Cascade Reactions Postulated to Occur at the Active Site of Ribonucleotide Reductases ${ }^{1}$. J. Am. Chem. Soc. 1999, 121, 1425-1433. [CrossRef]

80. Chandraratna, R.A.S.; Bayerque, A.L.; Okamura, W.H. The 12-s-cis Conformationally Locked 11-cis-Retinoids: A Delineation of the Thermal Requirements for [1,5]-Sigmatropic Shifts and Electrocyclizations in the Vitamin A Series and Novel Spectral Properties. J. Am. Chem. Soc. 1983, 105, 3588-3594. [CrossRef]

81. Alabugin, I.V.; Maroharan, M.; Breiner, B.; Lewis, F.D. Control of Kinetics and Thermodynamics of [1,5]-Shifts by Aromaticity: A View through the Prism of Marcus Theory. J. Am. Chem. Soc. 2003, 125, 9329-9342. [CrossRef] [PubMed]

82. Kless, A.; Nendel, M.; Willsey, S.; Houk, K.N. Origin of the Preference for the Orbital Symmetry Forbidden Stereochemistry of the 1,5-Sigmatropic Shift of Substituted Norcaradienes. J. Am. Chem. Soc. 1999, 121, 4524-4525. [CrossRef]

83. Karad, S.N.; Liu, R.-S. Gold-Catalyzed 1,2-Oxoarylations of Nitriles with Pyridine-Derived Oxides. Angew. Chem. Int. Ed. 2014, 53, 5444-5448. [CrossRef]

84. Zheng, Y.; Zhang, J.; Cheng, X.; Xu, X.; Zhang, L. Wolff Rearrangement of Oxidatively Generated $\alpha$-Oxo Gold Carbenes: An Effective Approach to Silylketenes. Angew. Chem. Int. Ed. 2019, 58, 5241-5245. [CrossRef] [PubMed]

85. Wetzel, A.; Gagosz, F. Gold-Catalyzed Transformation of 2-Alkynyl Arylazides: Efficient Access to the Valuable Pseudoindoxyl and Indolyl Frameworks. Angew. Chem. Int. Ed. 2011, 50, 7354-7358. [CrossRef] [PubMed]

86. Li, C.; Zhang, L. Gold-Catalyzed Nitrene Transfer to Activated Alkynes: Formation of $\alpha, \beta$-Unsaturated Amidines. Org. Lett. 2011, 13, 1738-1741. [CrossRef] [PubMed]

87. Gronnier, C.; Boissonnat, G.; Gagosz, F. Au-Catalyzed Formation of Functionalized Quinolines from 2-Alkynyl Arylazide Derivatives. Org. Lett. 2013, 15, 4234-4237. [CrossRef]

88. Shiroodi, R.K.; Gevorgyan, V. Metal-Catalyzed Double Migratory Cascade Reactions of Propargylic Esters and Phosphates. Chem. Soc. Rev. 2013, 42, 4991-5001. [CrossRef]

89. Wang, S.; Zhang, G.; Zhang, L. Gold-Catalyzed Reaction of Propargylic Carboxylates via An Initial 3, 3-Rearrangement. Synlett 2010, 692-706.

90. Li, N.; Wang, T.-Y.; Gong, L.-Z.; Zhang, L. Gold-Catalyzed Multiple Cascade Reaction of 2-Alkynylphenylazides with Propargyl Alcohols. Chem. Eur. J. 2015, 21, 3585-3588. [CrossRef]

91. Sherry, B.D.; Toste, F.D. Gold(I)-Catalyzed Propargyl Claisen Rearrangement. J. Am. Chem. Soc. 2004, 126, 15978-15979. [CrossRef] [PubMed]

92. Patil, N.T.; Lutete, L.M.; Nishina, N.; Yamamoto, Y. Gold-Catalyzed Intramolecular Hydroamination of Allenes: A Case of Chirality Transfer. Tetrahedron Lett. 2006, 47, 4749-4751. [CrossRef]

93. LaLonde, R.L.; Sherry, B.D.; Kang, E.J.; Toste, F.D. Gold(I)-Catalyzed Enantioselective Intramolecular Hydroamination of Allenes. J. Am. Chem. Soc. 2007, 129, 2452-2453. [CrossRef] [PubMed]

94. Kinder, R.E.; Zhang, Z.; Widenhoefer, R.A. Intermolecular Hydroamination of Allenes with N-Unsubstituted Carbamates Catalyzed by A Gold(I) N-Heterocyclic Carbene Complex. Org. Lett. 2008, 10, 3157-3159. [CrossRef] [PubMed]

95. Butler, K.L.; Tragni, M.; Widenhoefer, R.A. Gold(I)- Catalyzed Stereoconvergent, Intermolecular Enantioselective Hydroamination of Allenes. Angew. Chem. Int. Ed. 2012, 51, 5175-5178. [CrossRef] [PubMed]

96. Higginbotham, M.C.M.; Bebbington, M.W.P. Gold(I)-Catalysed Synthesis of Cyclic Sulfamidates by Intramolecular Allene Hydroamination. Chem. Commun. 2012, 48, 7565-7567. [CrossRef] 
97. Pflästerer, D.; Dolbundalchok, P.; Rafique, S.; Rudolph, M.; Rominger, F.; Hashmi, A.S.K. On the Gold-Catalyzed Intramolecular 7-Exo-Trig Hydroamination of Allenes. Adv. Synth. Catal. 2013, 355, 1383-1393. [CrossRef]

98. Shu, C.; Wang, Y.-H.; Zhou, B.; Li, X.-L.; Ping, Y.-F.; Lu, X.; Ye, L.-W. Generation of $\alpha$-Imino Gold Carbenes through Gold-Catalyzed Intermolecular Reaction of Azides with Ynamides. J. Am. Chem. Soc. 2015, 137, 9567-9570. [CrossRef]

99. Shu, C.; Wang, Y.-H.; Shen, C.-H.; Ruan, P.-P.; Lu, X.; Ye, L.-W. Gold-Catalyzed Intermolecular Ynamide Amination-Initiated Aza Nazarov Cyclization: Access to Functionalized 2-Aminopyrroles. Org. Lett. 2016, 18, 3254-3257. [CrossRef] [PubMed]

100. Dateer, R.B.; Shaibu, B.S.; Liu, R.-S. Gold-Catalyzed Intermolecular [4+2] and [2+2+2] Cycloadditions of Ynamides with Alkenes. Angew. Chem. Int. Ed. 2012, 51, 113-117. [CrossRef]

101. Jiménez-Núñez, E.; Echavarren, A.M. Gold-Catalyzed Cycloisomerizations of Enynes: A Mechanistic Perspective. Chem. Rev. 2008, 108, 3326-3350. [CrossRef] [PubMed]

102. Gorin, D.J.; Sherry, B.D.; Toste, F.D. Ligand Effects in Homogeneous Au Catalysis. Chem. Rev. 2008, 108, 3351-3378. [CrossRef]

103. Hashmi, A.S.K. Gold-Catalyzed Organic Reactions. Chem. Rev. 2007, 107, 3180-3211. [CrossRef] [PubMed]

104. Patil, N.T.; Yamamoto, Y. Coinage Metal-Assisted Synthesis of Heterocycles. Chem. Rev. 2008, 108, 3395-3442. [CrossRef] [PubMed]

105. Hashmi, A.S.K.; Blanco, M.C.; Kurpejovic, E.; Frey, W.; Bats, J.W. Gold Catalysis: First Applications of Cationic Binuclear Gold (I) Complexes and the First Intermolecular Reaction of An Alkyne with A Furan. Adv. Synth. Catal. 2006, 348, 709-713. [CrossRef]

106. Fürstner, A.; Davies, P.W. Catalytic Carbophilic Activation: Catalysis by Platinum and Gold $\pi$ Acids. Angew. Chem. Int. Ed. 2007, 46, 3410-3449. [CrossRef] [PubMed]

107. López-Carrillo, V.; Echavarren, A.M. Gold (I)-Catalyzed Intermolecular [2+2] Cycloaddition of Alkynes with Alkenes. J. Am. Chem. Soc. 2010, 132, 9292-9294. [CrossRef]

108. Sohel, S.M.A.; Liu, R.-S. Carbocyclisation of Alkynes with External Nucleophiles Catalysed by Gold, Platinum and other Electrophilic Metals. Chem. Soc. Rev. 2009, 38, 2269-2281. [CrossRef]

109. Karad, S.N.; Bhunia, S.; Liu, R.-S. Retention of Stereochemistry in Gold-Catalyzed Formal [4+3] Cycloaddition of Epoxides with Arenynamides. Angew. Chem. Int. Ed. 2012, 51, 8722-8726. [CrossRef]

110. Lee, J.-T.; Thomas, P.J.; Alper, H. Synthesis of $\beta$-Lactones by the Regioselective, Cobalt and Lewis Acid Catalyzed Carbonylation of Simple and Functionalized Epoxides. J. Org. Chem. 2001, 66, 5424-5426. [CrossRef]

111. Calet, S.; Urso, F.; Alper, H. Enantiospecific and Stereospecific Rhodium(I)-Catalyzed Carbonylation and Ring Expansion of Aziridines. Asymmetric Synthesis of Beta.-Lactams and the Kinetic Resolution of Aziridines. J. Am. Chem. Soc. 1989, 111, 931-934. [CrossRef]

112. Jin, H.; Huang, L.; Xie, J.; Rudolph, M.; Rominger, F.; Hashmi, A.S.K. Gold-Catalyzed C-H Annulation of Anthranils with Alkynes: A Facile, Flexible, and Atom-Economical Synthesis of Unprotected 7-Acylindoles. Angew. Chem. Int. Ed. 2016, 55, 794-797. [CrossRef] [PubMed]

113. Bai, Y.-B.; Luo, Z.; Wang, Y.; Gao, J.-M.; Zhang, L. Au-Catalyzed Intermolecular [2+2] Cycloadditions between Chloroalkynes and Unactivated Alkenes. J. Am. Chem. Soc. 2018, 140, 5860-5865. [CrossRef] [PubMed]

114. Nishimura, A.; Ohashi, M.; Ogoshi, S. Nickel-Catalyzed Intermolecular [2+2] Cycloaddition of Conjugated Enynes with Alkenes. J. Am. Chem. Soc. 2012, 134, 15692-15695. [CrossRef] [PubMed]

115. Snider, B.B.; Roush, D.M. Aluminum Chloride Catalyzed Reactions of Methyl Chloropropiolate with Unactivated Alkenes. J. Am. Chem. Soc. 1979, 101, 1906-1907. [CrossRef]

116. Koldobskii, A.B.; Solodova, E.V.; Godovikov, I.A.; Kalinin, V.N. Synthesis and Unusual [2+2]-Cycloaddition Reactions of Ethyl 4-Chloro-2-Oxobut-3-Ynoate with Unactivated Alkenes. Tetrahedron 2008, 64, 9555-9560. [CrossRef]

(C) 2020 by the authors. Licensee MDPI, Basel, Switzerland. This article is an open access article distributed under the terms and conditions of the Creative Commons Attribution (CC BY) license (http://creativecommons.org/licenses/by/4.0/). 